\title{
Global 7 km mesh nonhydrostatic Model Intercomparison Project for improving TYphoon forecast (TYMIP-G7): experimental design and preliminary results
}

\author{
Masuo Nakano ${ }^{1}$, Akiyoshi Wada ${ }^{2}$, Masahiro Sawada ${ }^{2}$, Hiromasa Yoshimura ${ }^{2}$, Ryo Onishi ${ }^{1}$, Shintaro Kawahara ${ }^{1}$, \\ Wataru Sasaki ${ }^{1}$, Tomoe Nasuno ${ }^{1}$, Munehiko Yamaguchi ${ }^{2}$, Takeshi Iriguchi ${ }^{2}$, Masato Sugi ${ }^{2}$, and Yoshiaki Takeuchi ${ }^{2}$ \\ ${ }^{1}$ Japan Agency for Marine-Earth Science and Technology, 3173-25 Showa-machi, Kanazawa-ku, \\ Yokohama, Kanagawa 236-0001, Japan \\ ${ }^{2}$ Meteorological Research Institute, Japan Meteorological Agency, 1-1 Nagamine, Tsukuba, Ibaraki 305-0052, Japan
}

Correspondence to: Masuo Nakano (masuo@jamstec.go.jp)

Received: 11 July 2016 - Discussion started: 2 August 2016

Revised: 3 February 2017 - Accepted: 3 February 2017 - Published: 31 March 2017

\begin{abstract}
Recent advances in high-performance computers facilitate operational numerical weather prediction by global hydrostatic atmospheric models with horizontal resolutions of $\sim 10 \mathrm{~km}$. Given further advances in such computers and the fact that the hydrostatic balance approximation becomes invalid for spatial scales $<10 \mathrm{~km}$, the development of global nonhydrostatic models with high accuracy is urgently required.

The Global $7 \mathrm{~km}$ mesh nonhydrostatic Model Intercomparison Project for improving TYphoon forecast (TYMIPG7) is designed to understand and statistically quantify the advantages of high-resolution nonhydrostatic global atmospheric models to improve tropical cyclone (TC) prediction. A total of 137 sets of 5-day simulations using three next-generation nonhydrostatic global models with horizontal resolutions of $7 \mathrm{~km}$ and a conventional hydrostatic global model with a horizontal resolution of $20 \mathrm{~km}$ were run on the Earth Simulator. The three $7 \mathrm{~km}$ mesh nonhydrostatic models are the nonhydrostatic global spectral atmospheric Double Fourier Series Model (DFSM), the Multi-Scale Simulator for the Geoenvironment (MSSG) and the Nonhydrostatic ICosahedral Atmospheric Model (NICAM). The $20 \mathrm{~km}$ mesh hydrostatic model is the operational Global Spectral Model (GSM) of the Japan Meteorological Agency.

Compared with the $20 \mathrm{~km}$ mesh GSM, the $7 \mathrm{~km}$ mesh models reduce systematic errors in the TC track, intensity and wind radii predictions. The benefits of the multi-model ensemble method were confirmed for the $7 \mathrm{~km}$ mesh nonhy-
\end{abstract}

drostatic global models. While the three $7 \mathrm{~km}$ mesh models reproduce the typical axisymmetric mean inner-core structure, including the primary and secondary circulations, the simulated TC structures and their intensities in each case are very different for each model. In addition, the simulated track is not consistently better than that of the $20 \mathrm{~km}$ mesh GSM. These results suggest that the development of more sophisticated initialization techniques and model physics is needed to further improve the TC prediction.

\section{Introduction}

\subsection{Global model}

Global models provide fundamental information for operational weather forecasting at daily, weekly and seasonal timescales. Moreover, such models produce initial and lateral boundary conditions to limited-area models, which furnish fundamental information for local-scale weather forecasts. Therefore, operational numerical weather prediction centres have been developing sophisticated global models with high resolution and accuracy. Because such models require huge computational resources, their development strongly depends on advances in high-performance computers. Recent computer progress has facilitated the reasonable operation of global models with horizontal resolutions of $\sim 10 \mathrm{~km}$. Indeed, the European Centre for Medium-Range Weather 
Forecasts (ECMWF) has operated a global model with a horizontal resolution of $9 \mathrm{~km}$ since March 2016. Therefore, sooner or later, it is expected that all numerical weather prediction centres will operate global models with horizontal grid intervals of $<10 \mathrm{~km}$.

Developing high-resolution models with a horizontal grid spacing of $<10 \mathrm{~km}$ must resolve three challenges. The first is to use a nonhydrostatic equation system. In the Earth's atmosphere, hydrostatic balance is established for spatial scales $>10 \mathrm{~km}$ with high accuracy. Therefore, the primitive equation system, which approximates the vertical momentum equation with the hydrostatic balance equation, has been used in conventional global models. The second challenge is to use a dynamical core that effectively runs on state-of-theart, massively parallel computer systems. Many conventional global models use the spectral method in which the Legendre transform is used for the meridional expansion of certain prognostic variables. Because the computational cost of this transform increases with the third power of the number of grid points and communication costs become large, one solution is to avoid such transforms (Tomita et al., 2001). The last challenge is to implement sophisticated physical schemes suitable for high-resolution models, especially for clouds, because they can be partially resolved in a model with a horizontal resolution of $10 \mathrm{~km}$.

Because developing operational numerical weather prediction models with high accuracy requires huge computational and human resources, the concept of transition of research to operations (R2O) has recently been encouraged. For example, the Hurricane Weather Research and Forecasting Model (Bernardet et al., 2015) and an atmosphere-ocean coupled limited-area model (Ito et al., 2015) have been developed based on R2O in the United States and Japan, respectively. In Japan, two next-generation, nonhydrostatic global atmospheric models have already been developed and used in the research community. These are called the Multi-Scale Simulator for the Geoenvironment (MSSG) and the Nonhydrostatic ICosahedral Atmospheric Model (NICAM). In addition, the Meteorological Research Institute (MRI) of the Japan Meteorological Agency (JMA) has developed a nextgeneration nonhydrostatic atmospheric model called the nonhydrostatic global spectral atmospheric Double Fourier Series Model (DFSM). To gain knowledge, to develop and improve nonhydrostatic global models and to share them with the research and operational communities are some aims of the present project.

\subsection{TC forecasts}

Tropical cyclones (TCs) are characterized by violent winds and torrential rain. These events cause tremendous damage to human lives, property and socioeconomic activity via landslides, floods and storm surges. Because an average of 26 TCs (>30\% of the global average) form in the western North Pacific each year, accurate TC track and intensity fore- casts are of great concern to east Asian countries to mitigate the impacts of the associated disasters. The JMA has the primary responsibility for TC forecasts in the western North Pacific region as a Regional Specialized Meteorological Centre (RSMC) of the World Meteorological Organization. The JMA has operated a $20 \mathrm{~km}$ mesh global atmospheric model to predict weather and TC tracks and intensities since 2007. Therefore, upgrading their global atmospheric model is a promising approach to improve TC forecasts in the western North Pacific.

Errors in TC track prediction by the JMA operational global atmospheric model at a given lead time have decreased on an average by half over the past 20 years (JMA, 2014) as the operational model has been upgraded. For example, TC track prediction error in a $30 \mathrm{~h}$ forecast with a $60 \mathrm{~km}$ mesh global model was $\sim 200 \mathrm{~km}$ in 1997 and decreased to $\sim 100 \mathrm{~km}$ in 2010 with a $20 \mathrm{~km}$ mesh model. Even though we have continuously improved TC track prediction, abnormally large track prediction errors called "forecast busts" (e.g. Carr and Elsberry, 2000) still occur. Typhoons Conson (2004) (Yamaguchi et al., 2009) and Fengshen (2008) (Yamada et al., 2016; Nasuno et al., 2016) are typical examples. Tracks predicted by tens-of-kilometres mesh global models for Fengshen predicted recurvature far from the Philippines; however, the typhoon made landfall in the Philippines according to best-track analyses (Joint Typhoon Warning Center, 2008). Yamada et al. (2016) reported that a $3.5 \mathrm{~km}$ mesh nextgeneration nonhydrostatic global model successfully simulated its landfall in the Philippines. Increases in the horizontal resolution of global atmospheric models with appropriate physical schemes can potentially reduce bust cases and annual mean errors of TC track predictions.

Despite the advances in TC track prediction, improvements in TC intensity predictions by global atmospheric models remain a challenge. One factor that impedes improvement in the intensity prediction is the lack of horizontal resolution to capture essential mechanisms of TC intensity changes. TC intensity and its variation are closely related to the inner-core structure and convective activity (e.g. Rogers et al., 2013; Wang and Wang, 2014). Recent studies using a high-resolution, limited-area atmospheric model show that the use of a horizontal resolution of a few kilometres is necessary to realistically reproduce the inner-core structure and associated convection (e.g. Braun and Tao, 2000; Gentry and Lackmann, 2010; Kanada and Wada, 2015). Fierro et al. (2009) examined the dependence of TC intensity prediction using horizontal resolutions from 30 to $1 \mathrm{~km}$ and pointed out that the predicted TC intensity became increasingly realistic with resolutions between 15 and $5 \mathrm{~km}$. Therefore, the use of a high-resolution global atmospheric model with a horizontal resolution of $<10 \mathrm{~km}$ is promising for improving TC intensity and track prediction. 


\subsection{TYMIP-G7}

The primary objectives of the Global $7 \mathrm{~km}$ mesh nonhydrostatic Model Intercomparison Project for improving TYphoon forecast (TYMIP-G7) are to understand and statistically quantify the advantages of high-resolution global atmospheric models towards the improvement of TC track and intensity forecasts. The project is conducted as a strategic program of the Earth Simulator of the Japan Agency for MarineEarth Science and Technology (JAMSTEC). We accomplish this objective via a model intercomparison of three $7 \mathrm{~km}$ mesh nonhydrostatic atmospheric models (DFSM, MSSG and NICAM) and a $20 \mathrm{~km}$ mesh hydrostatic operational atmospheric model of the JMA (Global Spectral Model; GSM) in various cases. Because a huge amount of data is produced by each model, we developed an effective method to handle and visualize the data. Sharing the knowledge obtained in this project with research and operational communities will facilitate $\mathrm{R} 2 \mathrm{O}$.

In this paper, we describe the specifications of TYMIPG7 and the set of metrics used to validate the model performances. Some preliminary results concerning the metrics are also shown. This paper comprises six sections. Section 2 describes the common experimental design, including the cases and the output dataset. Section 3 briefly overviews the scientific outcomes of each model and describes the detailed specifications. Section 4 presents the metrics, analysis method and visualization. Preliminary results concerning the advantages of high-resolution models for TC prediction and the simulated TC wind structure are given in Sect. 5. Section 6 is devoted to conclusions and future work.

\section{Experimental design}

We imitated JMA operational specifications to conduct 5day numerical experiments with the models (DFSM, GSM, MSSG and NICAM). The JMA 6-hourly global objective analysis data were used for each model to derive atmospheric initial conditions. The data were provided based on the GSM grid system, a linear Gaussian grid with a horizontal resolution of $20 \mathrm{~km}$ and a hybrid sigma-pressure vertical coordinate. DFSM and GSM interpolated data directly onto their model grids, whereas MSSG and NICAM preliminarily interpolated the data onto common latitude-longitude grids and pressure levels and then interpolated this to their model grids. A merged satellite and in situ data global daily sea surface temperature (SST) product with a horizontal resolution of $0.25^{\circ}$ (Kurihara et al., 2006) was used for the SST oceanic initial conditions and the sea ice concentration. Because an atmospheric model was used in the present study, SSTs for the 5-day integration were given as the boundary conditions. It was assumed that an SST anomaly from an observed daily climatology on an initial date persisted during the 5-day period. Even though no diurnal cycle of SST was input into the models, NICAM can simulate the diurnal cycle because it is coupled with a simple bulk ocean model, as described later.

The project was implemented using the Earth Simulator, a supercomputer system operated by JAMSTEC. The Earth Simulator is based on NEC SX-ACE, a distributed-memory, massively parallel vector system with a total of $5120 \mathrm{com}$ putational nodes. Each node has one central processing unit, which comprises four processing cores and a $64 \mathrm{~GB}$ main memory. The theoretical peak performance of the entire system is 1.3 peta floating-point operations per second.

\subsection{Cases}

We conducted the project for two stages: from June 2015 to September 2015 and from October 2015 to March 2016. The first stage addressed TCs from September to October in 2013, during the most active TC season since 1951. We forecasted nine TCs in 52 runs (Table 1). However, we detected some flaws in MSSG and NICAM, and we could not perform some of the numerical experiments. The second stage addressed the life cycle of a TC, e.g. genesis, rapid intensification, recurvature and extratropical transition in addition to the Madden-Julian oscillation (MJO; Madden and Julian, 1972) and the boreal summer intraseasonal oscillation (BSISO; Wang and Rui, 1990; Wang and Xie, 1997). After we improved the detected flaws, we examined 13 TCs in 85 runs (Table 2) in addition to the numerical experiments in the first stage. We analyse the model output obtained in the second stage in this paper.

\subsection{Dataset}

Model output data for every 1 or $3 \mathrm{~h}$ from each experiment (Tables 1 and 2) were stored for analyses. The components of the output are listed in Table 3. Even though each model uses its own grid system, the output data were prepared for a regular latitude-longitude (lat-long) grid system. In TYMIPG7, we used GrADS file formats (pairs of 4-byte IEEE 754 floating-point standard with a big-endian binary file and a control file in text format) that are common in the atmospheric and oceanic research fields. The domain of the output data covers the globe, including the western North $\mathrm{Pa}$ cific Ocean $\left(100-180^{\circ}\right.$ E, $\left.0-60^{\circ} \mathrm{N}\right)$. For the MJO and BSISO cases (20 runs; see Tables 1 and 2), it also covers the tropics $\left(30^{\circ} \mathrm{E}-100^{\circ} \mathrm{W}, 15^{\circ} \mathrm{S}-30^{\circ} \mathrm{N}\right)$. The horizontal resolution of the global dataset is $1.25^{\circ}$. The data for the western North Pacific Ocean and the tropics are prepared with a horizontal resolution of $\sim 0.07^{\circ}(7 \mathrm{~km})$ by DFSM, MSSG and NICAM and $\sim 0.19^{\circ}(20 \mathrm{~km})$ by GSM. In the vertical direction, the data were prepared on 32 common pressure levels (in $\mathrm{hPa}$ : $1000,975,950,925,900,875,850,825,800,775,750,700$, $650,600,550,500,450,400,350,300,250,225,200,175$, $150,125,100,70,50,30,20$ and 10). 
Table 1. List of initial times for stage 1 of TYMIP-G7. Typhoon cases in italic font are weaker than a tropical storm and those in bold italic font are extratropical cyclones.

\begin{tabular}{|c|c|c|c|c|c|c|c|}
\hline & Initial time & & Typhoon case & DFSM & GSM & MSSG & NICAM \\
\hline 1 & 12 September 2013 & 00:00:00 UTC & Man-yi & 0 & $\bigcirc$ & 0 & 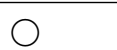 \\
\hline 2 & 12 September 2013 & 06:00:00 UTC & Man-yi & $\bigcirc$ & 0 & 0 & 0 \\
\hline 3 & 12 September 2013 & 12:00:00 UTC & Man-yi & $\bigcirc$ & $\bigcirc$ & 0 & \\
\hline 4 & 12 September 2013 & 18:00:00 UTC & Man-yi & 0 & 0 & 0 & \\
\hline 5 & 13 September 2013 & 00:00:00 UTC & Man-yi & & 0 & 0 & \\
\hline 6 & 30 September 2013 & 00:00:00 UTC & Wutip, Sepat, Fitow & 0 & & 0 & \\
\hline 7 & 30 September 2013 & 06:00:00 UTC & Wutip, Sepat, Fitow & & 0 & 0 & \\
\hline 8 & 30 September 2013 & 12:00:00 UTC & Wutip, Sepat, Fitow & 0 & 0 & & \\
\hline 9 & 30 September 2013 & 18:00:00 UTC & Wutip, Sepat, Fitow & 0 & 0 & 0 & \\
\hline 10 & 1 October 2013 & 00:00:00 UTC & Wutip, Sepat, Fitow, Danas & 0 & & & \\
\hline 11 & 1 October 2013 & 06:00:00 UTC & Sepat, Fitow, Danas & & 0 & 0 & \\
\hline 12 & 1 October 2013 & 12:00:00 UTC & Sepat, Fitow, Danas & & 0 & 0 & $\bigcirc^{*}$ \\
\hline 13 & 1 October 2013 & 18:00:00 UTC & Sepat, Fitow, Danas & 0 & 0 & 0 & * \\
\hline 14 & 2 October 2013 & 00:00:00 UTC & Sepat, Fitow, Danas & $\bigcirc$ & $\bigcirc$ & 0 & $b^{*}$ \\
\hline 15 & 2 October 2013 & 06:00:00 UTC & Sepat, Fitow, Danas & & 0 & 0 & \\
\hline 16 & 2 October 2013 & 12:00:00 UTC & Sepat, Fitow, Danas & & $\bigcirc$ & 0 & \\
\hline 17 & 2 October 2013 & 18:00:00 UTC & Sepat, Fitow, Danas & & & ○ & * \\
\hline 18 & 3 October 2013 & 00:00:00 UTC & Sepat, Fitow, Danas & & 0 & 0 & \\
\hline 19 & 3 October 2013 & 06:00:00 UTC & Sepat, Fitow, Danas & 0 & 0 & & \\
\hline 20 & 3 October 2013 & 12:00:00 UTC & Sepat, Fitow, Danas & 0 & 0 & 0 & \\
\hline 21 & 3 October 2013 & 18:00:00 UTC & Sepat, Fitow, Danas & 0 & 0 & 0 & S* \\
\hline 22 & 4 October 2013 & 00:00:00 UTC & Fitow, Danas & & 0 & 0 & * \\
\hline 23 & 9 October 2013 & 00:00:00 UTC & Danas, Nari, Wipha & & $\bigcirc$ & 0 & \\
\hline 24 & 9 October 2013 & 06:00:00 UTC & Danas, Nari, Wipha & 0 & 0 & 0 & \\
\hline 25 & 9 October 2013 & 12:00:00 UTC & Nari, Wipha & & & O & \\
\hline 26 & 9 October 2013 & 18:00:00 UTC & Nari, Wipha & 0 & & 0 & \\
\hline 27 & 10 October 2013 & 00:00:00 UTC & Nari, Wipha & & 0 & 0 & \\
\hline 28 & 10 October 2013 & 06:00:00 UTC & Nari, Wipha & & $\bigcirc$ & 0 & \\
\hline 29 & 10 October 2013 & 12:00:00 UTC & Nari, Wipha & & 0 & 0 & \\
\hline 30 & 10 October 2013 & 18:00:00 UTC & Nari, Wipha & & 0 & b & \\
\hline 31 & 11 October 2013 & 00:00:00 UTC & Nari, Wipha & 0 & 0 & b & \\
\hline 32 & 11 October 2013 & 06:00:00 UTC & Nari, Wipha & & & & \\
\hline 33 & 11 October 2013 & 12:00:00 UTC & Nari, Wipha & & O & 0 & S \\
\hline 34 & 11 October 2013 & 18:00:00 UTC & Nari, Wipha & & & 0 & \\
\hline 35 & 12 October 2013 & 00:00:00 UTC & Nari, Wipha & & 0 & b & \\
\hline 36 & 12 October 2013 & 06:00:00 UTC & Nari, Wipha & & & & \\
\hline 37 & 12 October 2013 & 12:00:00 UTC & Nari, Wipha & & & b & \\
\hline 38 & 17 October 2013 & 12:00:00 UTC & Wipha, Francisco & & & & \\
\hline 39 & 17 October 2013 & 18:00:00 UTC & Wipha, Francisco & $u$ & & 0 & \\
\hline 40 & 18 October 2013 & 00:00:00 UTC & Wipha, Francisco & 0 & & & \\
\hline 41 & 18 October 2013 & 06:00:00 UTC & Wipha, Francisco & 0 & & & \\
\hline 42 & 18 October 2013 & 12:00:00 UTC & Wipha, Francisco & & & & \\
\hline 43 & 18 October 2013 & 18:00:00 UTC & Francisco & 0 & & 0 & \\
\hline 44 & 19 October 2013 & 00:00:00 UTC & Francisco, Lekima & & & & $\bigcirc^{*}$ \\
\hline 45 & 19 October 2013 & 06:00:00 UTC & Francisco, Lekima & 0 & & & $\bigcirc$ \\
\hline 46 & 19 October 2013 & 12:00:00 UTC & Francisco, Lekima & & & & \\
\hline 47 & 19 October 2013 & 18:00:00 UTC & Francisco, Lekima & 0 & & 0 & 0 \\
\hline 48 & 20 October 2013 & 00:00:00 UTC & Francisco, Lekima & 0 & & & \\
\hline 49 & 20 October 2013 & 06:00:00 UTC & Francisco, Lekima & 0 & 0 & 0 & 0 \\
\hline 50 & 20 October 2013 & 12:00:00 UTC & Francisco, Lekima & 0 & 0 & 0 & $\bigcirc^{*}$ \\
\hline 51 & 20 October 2013 & 18:00:00 UTC & Francisco, Lekima & 0 & 0 & 0 & 0 \\
\hline 52 & 21 October 2013 & 00:00:00 UTC & Francisco, Lekima & 0 & & 0 & 0 \\
\hline
\end{tabular}

* Rerun with the fixed version of MATSIRO (Sect. 2.2.3). 
Table 2. List of initial times for stage 2 of TYMIP-G7. Typhoon cases in italic font are weaker than a tropical storm and those in bold italic font are extratropical cyclones.

\begin{tabular}{|c|c|c|c|c|c|c|c|}
\hline & Initial time & & $\begin{array}{l}\text { Typhoon case and } \\
\text { MJO/BSISO case }\end{array}$ & DFSM & GSM & MSSG & NICAM* \\
\hline 1 & 6 June 2013 & 12:00:00 UTC & Yagi & 0 & 0 & 0 & 0 \\
\hline 2 & 7 June 2013 & 00:00:00 UTC & Yagi & 0 & 0 & 0 & 0 \\
\hline 3 & 7 June 2013 & 12:00:00 UTC & Yagi & 0 & 0 & 0 & 0 \\
\hline 4 & 8 June 2013 & 00:00:00 UTC & Yagi & 0 & 0 & 0 & 0 \\
\hline 5 & 8 June 2013 & 12:00:00 UTC & Yagi & 0 & 0 & 0 & 0 \\
\hline 6 & 9 June 2013 & 00:00:00 UTC & Yagi & 0 & 0 & 0 & 0 \\
\hline 7 & 9 June 2013 & 12:00:00 UTC & Yagi & 0 & 0 & 0 & 0 \\
\hline 8 & 10 June 2013 & 00:00:00 UTC & Yagi & 0 & $\bigcirc$ & 0 & 0 \\
\hline 9 & 10 June 2013 & 12:00:00 UTC & Yagi & 0 & 0 & 0 & 0 \\
\hline 10 & 11 June 2013 & 00:00:00 UTC & Yagi & 0 & 0 & 0 & 0 \\
\hline 11 & 3 November 2013 & 00:00:00 UTC & Krosa & 0 & 0 & 0 & 0 \\
\hline 12 & 3 November 2013 & 12:00:00 UTC & Krosa, Haiyan & 0 & 0 & 0 & 0 \\
\hline 13 & 4 November 2013 & 00:00:00 UTC & Krosa, Haiyan & 0 & 0 & 0 & 0 \\
\hline 14 & 4 November 2013 & 12:00:00 UTC & Krosa, Haiyan & 0 & 0 & 0 & 0 \\
\hline 15 & 5 November 2013 & 00:00:00 UTC & Haiyan & 0 & 0 & 0 & 0 \\
\hline 16 & 5 November 2013 & 12:00:00 UTC & Haiyan & 0 & 0 & 0 & 0 \\
\hline 17 & 6 November 2013 & 00:00:00 UTC & Haiyan & 0 & 0 & 0 & 0 \\
\hline 18 & 6 November 2013 & 12:00:00 UTC & Haiyan & 0 & 0 & 0 & 0 \\
\hline 19 & 7 November 2013 & 00:00:00 UTC & Haiyan & 0 & 0 & 0 & 0 \\
\hline 20 & 27 July 2014 & 12:00:00 UTC & Halong & 0 & 0 & 0 & 0 \\
\hline 21 & 28 July 2014 & 00:00:00 UTC & Halong & 0 & 0 & 0 & 0 \\
\hline 22 & 28 July 2014 & 12:00:00 UTC & Halong, Nakri & 0 & 0 & 0 & 0 \\
\hline 23 & 29 July 2014 & 00:00:00 UTC & Halong, Nakri & 0 & 0 & 0 & 0 \\
\hline 24 & 29 July 2014 & 12:00:00 UTC & Halong, Nakri & 0 & 0 & 0 & 0 \\
\hline 25 & 30 July 2014 & 00:00:00 UTC & Halong, Nakri & 0 & 0 & 0 & 0 \\
\hline 26 & 30 July 2014 & 12:00:00 UTC & Halong, Nakri & 0 & 0 & 0 & 0 \\
\hline 27 & 31 July 2014 & 00:00:00 UTC & Halong, Nakri & 0 & $\bigcirc$ & $\bigcirc$ & $\bigcirc$ \\
\hline 28 & 31 July 2014 & 12:00:00 UTC & Halong, Nakri & 0 & 0 & 0 & 0 \\
\hline 29 & 1 August 2014 & 00:00:00 UTC & Halong, Nakri & 0 & 0 & 0 & 0 \\
\hline 30 & 1 August 2014 & 12:00:00 UTC & Halong, Nakri & 0 & 0 & 0 & 0 \\
\hline 31 & 2 August 2014 & 00:00:00 UTC & Halong, Nakri & 0 & 0 & 0 & 0 \\
\hline 32 & 2 August 2014 & 12:00:00 UTC & Halong, Nakri & 0 & 0 & 0 & 0 \\
\hline 33 & 3 August 2014 & 00:00:00 UTC & Halong, Nakri & 0 & $\bigcirc$ & 0 & 0 \\
\hline 34 & 3 August 2014 & 12:00:00 UTC & Halong, Nakri & 0 & 0 & 0 & 0 \\
\hline 35 & 4 August 2014 & 00:00:00 UTC & Halong, Nakri & 0 & 0 & 0 & 0 \\
\hline 36 & 4 August 2014 & 12:00:00 UTC & Halong & 0 & 0 & 0 & $x$ \\
\hline 37 & 5 August 2014 & 00:00:00 UTC & Halong & 0 & 0 & 0 & $x$ \\
\hline 38 & 5 August 2014 & 12:00:00 UTC & Halong & 0 & 0 & 0 & 0 \\
\hline 39 & 6 August 2014 & 00:00:00 UTC & Halong & 0 & 0 & 0 & 0 \\
\hline 40 & 6 August 2014 & 12:00:00 UTC & Halong & 0 & 0 & 0 & 0 \\
\hline 41 & 7 March 2015 & 00:00:00 UTC & MJO & 0 & 0 & 0 & 0 \\
\hline 42 & 7 March 2015 & 12:00:00 UTC & MJO & 0 & 0 & 0 & 0 \\
\hline 43 & 8 March 2015 & 00:00:00 UTC & MJO & 0 & 0 & 0 & 0 \\
\hline 44 & 8 March 2015 & 12:00:00 UTC & MJO & 0 & $\bigcirc$ & 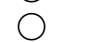 & 0 \\
\hline 45 & 9 March 2015 & 00:00:00 UTC & MJO & 0 & 0 & 0 & 0 \\
\hline 46 & 9 March 2015 & 12:00:00 UTC & MJO, Pam & 0 & 0 & 0 & 0 \\
\hline 47 & 10 March 2015 & 00:00:00 UTC & MJO, Pam & 0 & 0 & 0 & 0 \\
\hline 48 & 10 March 2015 & 12:00:00 UTC & MJO, Bavi, Pam & 0 & 0 & 0 & 0 \\
\hline 49 & 11 March 2015 & 00:00:00 UTC & MJO, Bavi, Pam & 0 & $\bigcirc$ & 0 & 0 \\
\hline 50 & 11 March 2015 & 12:00:00 UTC & MJO, Bavi, Pam & 0 & $\bigcirc$ & $\bigcirc$ & $\bigcirc$ \\
\hline 51 & 27 June 2015 & 00:00:00 UTC & BSISO & 0 & 0 & 0 & 0 \\
\hline 52 & 27 June 2015 & 12:00:00 UTC & BSISO & 0 & 0 & 0 & 0 \\
\hline 53 & 28 June 2015 & 00:00:00 UTC & BSISO & 0 & 0 & 0 & 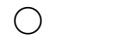 \\
\hline
\end{tabular}


Table 2. Continued.

\begin{tabular}{|c|c|c|c|c|c|c|c|}
\hline & Initial time & & $\begin{array}{l}\text { Typhoon case and } \\
\text { MJO/BSISO case }\end{array}$ & DFSM & GSM & MSSG & NICAM $^{*}$ \\
\hline 54 & 28 June 2015 & 12:00:00 UTC & BSISO & $\bigcirc$ & 0 & & \\
\hline 55 & 29 June 2015 & 00:00:00 UTC & BSISO & $\bigcirc$ & & & \\
\hline 56 & 29 June 2015 & 12:00:00 UTC & BSISO, Chan-hom & $\bigcirc$ & O & & \\
\hline 57 & 30 June 2015 & 00:00:00 UTC & BSISO, Chan-hom & $\bigcirc$ & & & \\
\hline 58 & 30 June 2015 & 12:00:00 UTC & BSISO, Chan-hom & $\bigcirc$ & & & \\
\hline 59 & 1 July 2015 & 00:00:00 UTC & BSISO, Chan-hom & $\bigcirc$ & & & \\
\hline 60 & 1 July 2015 & 12:00:00 UTC & BSISO, Chan-hom & $\bigcirc$ & & & \\
\hline 61 & 13 August 2015 & 12:00:00 UTC & & 0 & & & \\
\hline 62 & 14 August 2015 & 00:00:00 UTC & Molave, Goni, Atsani & $\bigcirc$ & & & \\
\hline 63 & 14 August 2015 & 12:00:00 UTC & Molave, Goni, Atsani & $\bigcirc$ & & 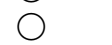 & \\
\hline 64 & 15 August 2015 & 00:00:00 UTC & Molave, Goni, Atsani & $\bigcirc$ & & & \\
\hline 65 & 15 August 2015 & 12:00:00 UTC & Molave, Goni, Atsani & $\bigcirc$ & $\bigcirc$ & O & \\
\hline 66 & 16 August 2015 & 00:00:00 UTC & Molave, Goni, Atsani & $\bigcirc$ & & & \\
\hline 67 & 16 August 2015 & 12:00:00 UTC & Molave, Goni, Atsani & $\bigcirc$ & $\bigcirc$ & $\checkmark$ & \\
\hline 68 & 17 August 2015 & 00:00:00 UTC & Molave, Goni, Atsani & $\bigcirc$ & & & \\
\hline 69 & 17 August 2015 & 12:00:00 UTC & Molave, Goni, Atsani & $\bigcirc$ & & & \\
\hline 70 & 18 August 2015 & 00:00:00 UTC & Molave, Goni, Atsani & $\bigcirc$ & & & \\
\hline 71 & 18 August 2015 & 12:00:00 UTC & Goni, Atsani & $\bigcirc$ & & & \\
\hline 72 & 19 August 2015 & 00:00:00 UTC & Goni, Atsani & $\bigcirc$ & $\bigcirc$ & $\bigcirc$ & \\
\hline 73 & 19 August 2015 & 12:00:00 UTC & Goni, Atsani & $\bigcirc$ & $\bigcirc$ & b & \\
\hline 74 & 20 August 2015 & 00:00:00 UTC & Goni, Atsani & $\bigcirc$ & & & \\
\hline 75 & 20 August 2015 & 12:00:00 UTC & Goni, Atsani & $\bigcirc$ & $\bigcirc$ & & \\
\hline 76 & 21 August 2015 & 00:00:00 UTC & Goni, Atsani & $\bigcirc$ & $\bigcirc$ & & \\
\hline 77 & 6 September 2015 & 00:00:00 UTC & Kilo, Etau & $\bigcirc$ & $\bigcirc$ & & \\
\hline 78 & 6 September 2015 & 12:00:00 UTC & Kilo, Etau & $\bigcirc$ & $\bigcirc$ & & \\
\hline 79 & 7 September 2015 & 00:00:00 UTC & Kilo, Etau & $\bigcirc$ & $\bigcirc$ & & \\
\hline 80 & 7 September 2015 & 12:00:00 UTC & Kilo, Etau & $\bigcirc$ & & & \\
\hline 81 & 8 September 2015 & 00:00:00 UTC & Kilo, Etau & $\bigcirc$ & $\bigcirc$ & 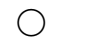 & 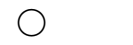 \\
\hline 82 & 8 September 2015 & 12:00:00 UTC & Kilo, Etau & $\bigcirc$ & $\bigcirc$ & $\bigcirc$ & $\bigcirc$ \\
\hline 83 & 9 September 2015 & 00:00:00 UTC & Kilo, Etau & $\bigcirc$ & 0 & $\bigcirc$ & $\checkmark$ \\
\hline 84 & 9 September 2015 & 12:00:00 UTC & Kilo, Etau & $\bigcirc$ & $\bigcirc$ & $\bigcirc$ & $\bigcirc$ \\
\hline 85 & 10 September 2015 & 00:00:00 UTC & Kilo, Etau & $\bigcirc$ & $\bigcirc$ & $\bigcirc$ & \\
\hline
\end{tabular}

* Run with the fixed version of MATSIRO (Sect. 2.2.3).

\section{Models}

We used three $7 \mathrm{~km}$ mesh nonhydrostatic global atmospheric models in TYMIP-G7 (Fig. 1). The DFSM was developed in the MRI of the JMA. The MSSG was developed at JAMSTEC. NICAM was developed at JAMSTEC, the University of Tokyo and the RIKEN Advanced Institute for Computational Science. In addition, we used GSM with a horizontal grid spacing of $\sim 20 \mathrm{~km}$ to quantify the advantages of the higher-resolution models. DFSM and GSM are spectral models and MSSG and NICAM are grid models. The following subsections detail the aforementioned models (Table 4) and the experimental design.

\subsection{GSM and DFSM}

GSM (JMA, 2013) is a hydrostatic global spectral atmospheric model using spherical harmonics. The JMA has used this model operationally to provide fundamental information for forecasts. The model was put into operation in 1988 with T63L16 resolution ( $200 \mathrm{~km}$ mesh), where " $\mathrm{T}_{x}$ " refers to the horizontal triangular spectral truncation with a total wavenumber $x$ using a quadratic Gaussian grid and " $\mathrm{L}_{y}$ " refers to the number of vertical layers $y$. The resolution of the operational GSM increased to T106L21 (120 km mesh) in 1989, T213L30 (60 km mesh) in 1996, T213L40 in 2001, TL319L40 (60 km mesh) in 2005, TL959L60 (20 km mesh) in 2007 and TL959L100 in 2014 (JMA, 2016), where "TL $x$ " refers to the horizontal triangular spectral truncation with a total wavenumber $x$ using a linear Gaussian grid (Hortal, 2002).

The JMA has also used GSM as the principal part of an ensemble prediction system for medium-range weather forecasts. The forecast data are widely provided via the framework of "The observing-system research and predictability experiment Interactive Grand Global Ensemble" (TIGGE) 
Table 3. Output variables and domains.

\begin{tabular}{|c|c|c|c|}
\hline Domain & Interval & Variable & $\begin{array}{l}\text { Horizontal } \\
\text { resolution }\end{array}$ \\
\hline \multirow[t]{4}{*}{ Global } & $1 \mathrm{~h}$ & $\begin{array}{l}\text { accumulated cloud ice (cldi), accumulated cloud water (cldw), outward } \\
\text { longwave radiation (olr), sea level pressure (psea), } 2 \mathrm{~m} \text { specific humid- } \\
\text { ity (qs), sea surface temperature (sst), total precipitable water (tpw), } \\
2 \mathrm{~m} \text { temperature (ts), } 10 \mathrm{~m} \text { zonal wind speed (us), } 10 \mathrm{~m} \text { meridional wind } \\
\text { speed (vs) }\end{array}$ & $1.25^{\circ}$ \\
\hline & $1 \mathrm{~h}$ (average) & $\begin{array}{l}\text { latent heat flux (fllh), zonal wind stress (flmu), meridional wind stress } \\
\text { (flmv), sensible heat flux (flsh), precipitation (prc), precipitation by } \\
\text { cumulus parameterization (prcc) }\end{array}$ & $1.25^{\circ}$ \\
\hline & $3 \mathrm{~h}$ & $\begin{array}{l}\text { cloud cover (cvr), cloud water content (cwc), cloud water (qc or xc), } \\
\text { cloud ice (qi or xi), rain water (qr or xr), snow (qs or xs), graupel (qg or } \\
\text { xg), specific humidity }(q) \text {, relative humidity (rh), temperature }(t) \text {, zonal } \\
\text { wind speed }(u) \text {, meridional wind speed }(v) \text {, vertical wind speed }(w) \text {, } \\
\text { height }(z)\end{array}$ & $1.25^{\circ}$ \\
\hline & $3 \mathrm{~h}$ (average) & $\begin{array}{l}\text { cumulus-induced heating (hrcv), cloud-induced heating (hrlc), } \\
\text { radiation-induced heating (hrr), turbulence-induced heating (hrvd), } \\
\text { cumulus-induced moistening (qrcv), cloud-induced moistening (qrlc), } \\
\text { radiation-induced heating (qrvd), cumulus-induced zonal acceleration } \\
\text { (urcv), turbulence-induced zonal acceleration (urvd), cumulus-induced } \\
\text { meridional acceleration (vrcv), turbulence-induced meridional acceler- } \\
\text { ation (vrvd) }\end{array}$ & $1.25^{\circ}$ \\
\hline \multirow{4}{*}{$\begin{array}{l}\text { Western North } \\
\text { Pacific/tropics }\end{array}$} & $1 \mathrm{~h}$ & cldi, cldw, olr, psea, qs, sst, tpw, ts, us, vs & $\sim 7 \mathrm{~km}$ \\
\hline & $1 \mathrm{~h}$ (average) & fllh, flmu, flmv, flsh, pre, prec & $\sim 7 \mathrm{~km}$ \\
\hline & $3 \mathrm{~h}$ & $\mathrm{cvr}, \mathrm{cwc}, q, \mathrm{rh}, t, u, v, w, z$ & $\sim 7 \mathrm{~km}$ \\
\hline & $3 \mathrm{~h}$ (average) & hrcv, hrlc, hrr, hrvd, qrev, qrlc, qrvd, urcv, urvd, vrev, vrvd & $\sim 7 \mathrm{~km}$ \\
\hline
\end{tabular}

for the research community. TIGGE data have been used for various applications, including TC track prediction (Yamaguchi et al., 2012, 2015) and the MJO (Matsueda and Endo, 2011). In addition, GSM has been used to produce atmospheric reanalysis datasets, i.e. the Japanese 25-year ReAnalysis (JRA-25; Onogi et al., 2007) and the Japanese 55-year ReAnalysis (JRA-55; Kobayashi et al., 2015). MRI global climate models have been developed based on GSM and have been used in climate research, such as global warming projections (e.g. Mizuta et al., 2006; Yukimoto et al., 2011) and stratospheric studies (e.g. Shibata et al., 1999). TC activity in future climates has been intensively studied using various model physics and horizontal resolutions (Murakami and Sugi, 2010; Murakami et al., 2012a, b).

The MRI developed DFSM by changing the hydrostatic dynamical core of GSM using spherical harmonics to a nonhydrostatic dynamical core using a double Fourier series (Yoshimura, 2012). DFSM uses the same basis functions of the double Fourier series as Cheong (2000). In DFSM, a fast Fourier transform is used instead of a Legendre transform in the meridional direction. Because the computational cost of the fast Fourier transform is much smaller than that of the Legendre transform, especially at high res-

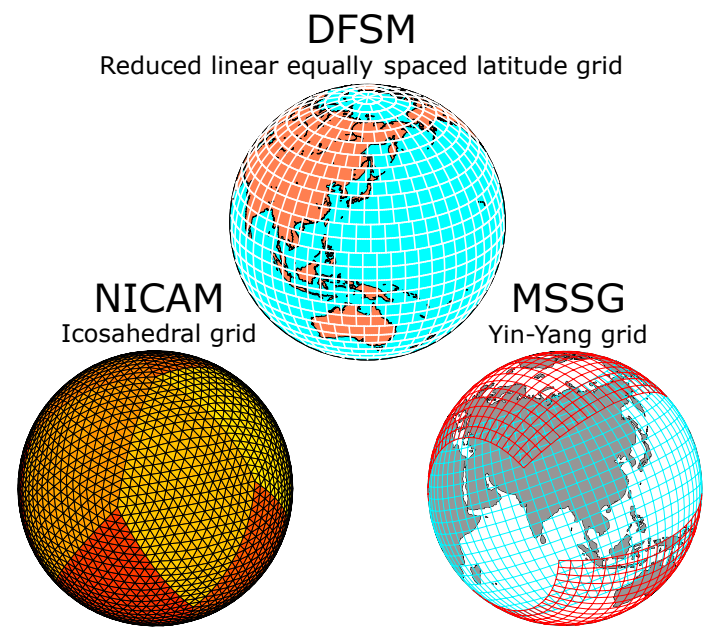

Figure 1. Schematic diagram of the horizontal grid structures of the three models used in TYMIP-G7.

olution, DFSM is applicable to finer-resolution simulations. DFSM gives nearly the same results as GSM using the Legendre transform; a comparison of 2-day forecasts using the 
Table 4. Brief description of the specifications for each global nonhydrostatic model.

\begin{tabular}{|c|c|c|c|c|}
\hline & DFSM & GSM & MSSG & NICAM \\
\hline Horizontal resolution & $7 \mathrm{~km}$ & $20 \mathrm{~km}$ & $7 \mathrm{~km}$ & $7 \mathrm{~km}$ \\
\hline $\begin{array}{l}\text { Horizontal grid } \\
\text { configuration }\end{array}$ & $\begin{array}{l}\text { Reduced linear equally } \\
\text { spaced latitude grid }\end{array}$ & $\begin{array}{l}\text { Reduced linear } \\
\text { Gaussian grid }\end{array}$ & Yin-Yang grid & Icosahedral grid \\
\hline $\begin{array}{l}\text { Number of grids in } \\
\text { horizontal direction }\end{array}$ & 8845592 & 1312360 & 11184128 & 10485760 \\
\hline Vertical coordinate & $\begin{array}{l}\text { Hybrid sigma-pressure } \\
\text { coordinate }\end{array}$ & $\begin{array}{l}\text { Hybrid sigma-pressure } \\
\text { coordinate }\end{array}$ & $\begin{array}{l}\text { Terrain-following } \\
\text { coordinate }\end{array}$ & $\begin{array}{l}\text { Terrain-following } \\
\text { coordinate }\end{array}$ \\
\hline Vertical levels & $\begin{array}{l}100 \text { (top: } 0.01 \mathrm{hPa}, \\
\text { bottom: } 999.0429 \mathrm{hPa}^{*} \\
(\sim 8 \mathrm{~m}))\end{array}$ & $\begin{array}{l}100 \text { (top: } 0.01 \mathrm{hPa}, \\
\text { bottom: } 999.0429 \mathrm{hPa}^{*} \\
(\sim 8 \mathrm{~m}))\end{array}$ & $\begin{array}{l}55 \text { (top: } 40 \mathrm{~km} \text {, } \\
\text { bottom: } 75 \mathrm{~m} \text { ) }\end{array}$ & $\begin{array}{l}38 \text { (top: } 36.7 \mathrm{~km} \text {, } \\
\text { bottom: } 80 \mathrm{~m} \text { ) }\end{array}$ \\
\hline Dynamical core & $\begin{array}{l}\text { Nonhydrostatic spectral } \\
\text { model using double } \\
\text { Fourier series }\end{array}$ & $\begin{array}{l}\text { Hydrostatic spectral } \\
\text { model using spherical } \\
\text { harmonics }\end{array}$ & $\begin{array}{l}\text { Nonhydrostatic grid } \\
\text { model using finite } \\
\text { difference method }\end{array}$ & $\begin{array}{l}\text { Nonhydrostatic grid } \\
\text { model using finite } \\
\text { volume method }\end{array}$ \\
\hline Time step (s) & 200 & 400 & Variable & 30 \\
\hline Cloud physics & Smith (1990) & Smith (1990) & $\begin{array}{l}\text { Onishi and Takahashi } \\
\text { (2012) }\end{array}$ & Tomita (2008) \\
\hline Cumulus convection & Randall and Pan (1993) & Randall and Pan (1993) & Not used & Not used \\
\hline $\begin{array}{l}\text { Planetary boundary } \\
\text { layer }\end{array}$ & $\begin{array}{l}\text { MY2 (Mellor and } \\
\text { Yamada, 1974, 1982) }\end{array}$ & $\begin{array}{l}\text { MY2 (Mellor and } \\
\text { Yamada, 1974, 1982) }\end{array}$ & $\begin{array}{l}\text { MYNN2.5 (Nakanishi } \\
\text { and Niino, 2009) }\end{array}$ & $\begin{array}{l}\text { MYNN2 (Nakanishi } \\
\text { and Niino, 2004; Noda } \\
\text { et al., 2010) }\end{array}$ \\
\hline Radiation & $\begin{array}{l}\text { JMA (2013), } \\
\text { Yabu (2013) }\end{array}$ & $\begin{array}{l}\text { JMA (2013), } \\
\text { Yabu (2013) }\end{array}$ & $\begin{array}{l}\text { MstranX } \\
\text { (Sekiguchi and } \\
\text { Nakajima, 2008) }\end{array}$ & $\begin{array}{l}\text { MstranX (Sekiguchi } \\
\text { and Nakajima, 2008) }\end{array}$ \\
\hline Land and ocean & SiB (JMA, 2013) & SiB (JMA, 2013) & $\begin{array}{l}\text { Bucket option: } \\
\text { 3-D ocean model }\end{array}$ & $\begin{array}{l}\text { MATSIRO } \\
\text { (Takata et al., 2003) } \\
\text { slab ocean model }\end{array}$ \\
\hline Surface boundary layer & $\begin{array}{l}\text { Louis et al. (1982), } \\
\text { Miller et al. (1989) } \\
\text { ocean/unstable } \\
\text { atmosphere }\end{array}$ & $\begin{array}{l}\text { Louis et al. (1982), } \\
\text { Miller et al. (1989) } \\
\text { ocean/unstable } \\
\text { atmosphere }\end{array}$ & $\begin{array}{l}\text { Zhang and Anthes } \\
\text { (1982) for land surface; } \\
\text { Fairall et al. (1996, } \\
\text { 2003) for ocean surface }\end{array}$ & Louis (1979) \\
\hline
\end{tabular}

* Full-level pressure for surface pressure $=1000 \mathrm{hPa}$.

$60 \mathrm{~km}$ resolution model was shown by Yoshimura and Matsumura (2005).

In GSM and DFSM, a two-time-level, semi-implicit, semiLagrangian scheme (e.g. Hortal, 2002) is used to facilitate long time steps for computational efficiency. The vertically conservative semi-Lagrangian scheme is used in the advection calculation (Yoshimura and Matsumura, 2003, 2005; Yukimoto et al., 2011), and a correction method similar to that described by Priestley (1993) and Gravel and Staniforth (1994) is used for global conservation in the material transport. To save computational costs, we used a reduced grid (Miyamoto, 2006) in which the number of zonal grid points is decreased, especially at high latitudes (Fig. 1).
Because the DFSM resolution is $\sim 7 \mathrm{~km}$ (ML2559L100; "ML $\mathrm{ML}_{x}$ " refers to a horizontal truncation with zonal wavenumber $x$ using a linear equally spaced latitude grid), the model applies the nonhydrostatic option, which essentially uses the same nonhydrostatic equations as used in the ALADINNH nonhydrostatic limited-area spectral model (Bubnová et al., 1995; Bénard et al., 2010) and the nonhydrostatic version of the Integrated Forecast System global model of ECMWF (Wedi and Smolarkiewicz, 2009). However, there are some differences in the method of integration. DFSM uses a non-constant coefficient semi-implicit scheme. The preconditioned generalized conjugate residual method, a fast-converging iteration method, is used to solve the simultaneous linear equations associated with the semi-implicit 
scheme (Yoshimura, 2012). Recalculation is necessary only for the non-constant linear terms during the iteration. It is found that only a single iteration is sufficient for convergence.

Physical packages included in GSM and DFSM are the same as those in the March 2014 version of the operational global atmospheric model of the JMA. A prognostic cumulus parameterization scheme (Randall and Pan, 1993) and other schemes in GSM are used in DFSM without any changes. The physical process is described in detail in the JMA (2013).

\subsection{MSSG}

MSSG is an atmosphere-ocean coupled nonhydrostatic model aimed at a seamless simulation from global to local scales (Takahashi et al., 2006, 2013). The MSSG comprises atmospheric (MSSG-A) and oceanic (MSSG-O) components. MSSG uses a conventional lat-long grid system for regional simulations and the Yin-Yang grid system (Kageyama and Sato, 2004; Baba et al., 2010), which comprises two overlapping lat-long grids to avoid the polar singularity problem, for global simulations. MSSG has been used in a wide range of applications. A cloud-system-resolving global ocean-atmosphere coupled MSSG successfully simulated an observed MJO propagation (Sasaki et al., 2016). A global atmosphere-ocean coupled experiment with $11 \mathrm{~km}$ horizontal resolution with a nested region with $2.7 \mathrm{~km}$ horizontal resolution simulated sea surface cooling caused by a TC along its track (Takahashi et al., 2013). High-resolution regional atmospheric simulations have been conducted to investigate the influence of the choice of cloud microphysics scheme and in-cloud turbulence on cloud development (Onishi et al., 2011, 2012). MSSG-O with a $2 \mathrm{~km}$ horizontal resolution has been used to investigate the dispersion of radionuclides released from the Fukushima Daiichi nuclear power plant (Choi et al., 2013) and the effect of wind on long-term summer water temperature trends in Tokyo Bay, Japan, with $200 \mathrm{~m}$ horizontal resolution (Lu et al., 2015). MSSG-A with a $5 \mathrm{~m}$ spatial resolution has been used in building-resolving urban atmosphere simulations to examine the heat environments of streets (Takahashi et al., 2013).

In this study, MSSG-A is exclusively used. Its dynamical core is based on the nonhydrostatic equations, and it predicts the three wind components, as well as air density and pressure. Each horizontal computational domain covers $4056 \times 1352$ grids in the Yin-Yang lat-long grid system. The average horizontal grid spacing is $7 \mathrm{~km}$. The vertical level comprises 55 vertical layers with a top height of $40 \mathrm{~km}$ and the lowermost vertical layer at $75 \mathrm{~m}$. The thirdorder Runge-Kutta scheme is used for time integration. The fast terms related to acoustic and gravity waves are calculated separately with a shorter time step (Wicker and Skamarock, 2002). A fifth-order upwind scheme (Wicker and Skamarock, 2002) was chosen for the momentum advection and a second- order weighted average flux scheme with the Superbee flux limiter (Toro, 1989) for the scalar advection. For turbulent diffusion, the Mellor-Yamada-Nakanishi-Niino level 2.5 scheme (Nakanishi and Niino, 2009) was used. The MSSGBulk model (Onishi and Takahashi, 2012), a six-category bulk cloud microphysics model, is used for explicit cloud physics. Model simulation radiation transfer code version 10 (MstranX; Sekiguchi and Nakajima, 2008) is used to calculate longwave and shortwave radiation transfer.

During the first stage of the project, extraordinary increases in precipitable water appeared in the 5-day integrations when the conventional bulk surface flux model of Zhang and Anthes (1982) was used for both land and ocean surfaces. This issue was solved by the use of the COARE 3.0 model (Fairall et al., 1996, 2003) for ocean surface fluxes with Zhang and Anthes (1982) being used only for land surface fluxes. This combination was used for all simulations in the second stage, and we plan to rerun all the simulations in the first stage.

\subsection{NICAM}

NICAM (Satoh et al., 2008, 2014) was developed as a climate model and can explicitly resolve clouds without any convective parameterization, which is known to be the most ambiguous component in conventional climate models (Randall et al., 2003). From the first appearance of realistic cloudresolving simulations using a $3.5 \mathrm{~km}$ mesh horizontal resolution by Miura et al. (2007a), NICAM has primarily been used to study tropical meteorological systems, such as the MJO (Miura et al., 2007b; Nasuno, 2013; Miyakawa et al., 2014), TC genesis from the MJO in boreal winter (Fudeyasu et al., 2008, 2010a, b), TC genesis from the BSISO in the western North Pacific (Oouchi et al., 2009; Nakano et al., 2015) and BSISO in the northern Indian Ocean (Taniguchi et al., 2010; Yanase et al., 2010). NICAM has also been used for quasi-real-time forecast systems during field observation campaigns to support field observations (Nasuno, 2013). Recent progress with high-performance computing infrastructures, such as the K-computer, a 10-petaflop supercomputer in Japan, facilitates $870 \mathrm{~m}$ mesh global simulations (Miyamoto et al., 2013, 2015; Kajikawa et al., 2016). This is the highest resolution to date (10 July 2016). Climate simulations (of 30 years) using a $14 \mathrm{~km}$ mesh model (Kodama et al., 2015) and large member (10 240 members) ensemble data assimilations based on an ensemble Kalman filter (Miyoshi et al., 2015) have also been executed.

NICAM uses an icosahedral grid system that covers the globe with a nearly uniform grid size, avoiding the polar singularity problem. Increased horizontal resolution is attained by recursively dividing horizontal grids in half. Therefore, the possible horizontal resolution is discrete and represented by the "g-level", which indicates the number of divisions of a horizontal grid. In this project, the 2014 version of NICAM (called NICAM.14.3) was used with a horizon- 
tal resolution of g-level 10 , corresponding to a $7 \mathrm{~km}$ mesh. The vertical level comprises 38 vertical layers to a top height of $36.7 \mathrm{~km}$ with the lowest layer at $80 \mathrm{~m}$. NICAM uses a fully compressible nonhydrostatic equation system for the dynamics of the atmosphere. The model uses an icosahedral grid system in the horizontal direction with the Arakawa Agrid and terrain-following coordinate with the Lorenz grid in the vertical direction. The equations are discretized using the flux form of the finite volume method. The numerical scheme guarantees conservation of total mass and energy. The second-order Runge-Kutta scheme is primarily used for time integration, whereas the third-order RungeKutta scheme is used in some cases to avoid computational instability. NICAM uses the split-explicit scheme together with the horizontal explicit and vertical implicit scheme to avoid the restriction of the Courant-Friedrichs-Lewy condition for acoustic waves. The NICAM Single-moment Water 6 cloud microphysics scheme (Tomita, 2008) is used for cloud microphysics without any convective parameterization. Planetary boundary layer processes are calculated using the Mellor-Yamada-Nakanishi-Niino level 2 scheme (Nakanishi and Niino, 2004) implemented and examined by Noda et al. (2010). Longwave and shortwave radiation transfer is calculated using MstranX (Sekiguchi and Nakajima, 2008). Land surface processes are computed by the Minimal Advanced Treatments of Surface Interaction and Runoff (MATSIRO; Takata et al., 2003). NICAM is coupled with a simple slab ocean model. This model calculates SST based on the local heat balance between the ocean slab and the atmosphere, and the other ocean dynamics, such as vertical mixing and advection, are not considered. The slab has a specific heat capacity determined by its thickness $(15 \mathrm{~m})$. The calculated SST is nudged with a persistent SST anomaly with an $e$-folding time of 7 days. The surface flux is calculated by the Louis (1979) scheme with sea surface roughness length parameterization by Moon et al. (2007).

During the first stage of this project, there were frequent problems of divisions by zero in MATSIRO that had not been experienced in simulations with coarser horizontal resolutions. This issue was fixed before simulations in the second stage, and abnormal cases in the first stage had to be rerun. The fix had a slight impact on the prediction results. During the second stage, however, two cases were still unable to be completed due to numerical instability (Table 2).

\section{Metrics, analysis methods and visualization}

\subsection{Metrics}

Here, we define the following metrics to evaluate the TC forecast performance:

1. computational resources for a 5-day forecast on the Earth Simulator (node hours),
2. TC track (position) error every $6 \mathrm{~h}$ of forecast time $(\mathrm{km})$,

3. TC intensity (central pressure) error every $6 \mathrm{~h}$ of forecast time (hPa),

4. averaged radius of surface $50-k n o t\left(25 \mathrm{~m} \mathrm{~s}^{-1}\right)$ wind (AR50) error $(\mathrm{km})$, and

5. averaged radius of surface $30-k n o t\left(15 \mathrm{~m} \mathrm{~s}^{-1}\right)$ wind (AR30) error $(\mathrm{km})$.

It is important for the operational model that the calculation is completed in less time with smaller computational resources so that we applied metric (1). The metrics (2)-(5) measure the accuracy of the track, intensity and surface wind structure prediction based on the RSMC Tokyo best-track data.

\subsection{TC tracking}

We extract TC tracks from the model experiments using the hourly mean sea level pressure (SLP) data with a horizontal resolution of $\sim 7 \mathrm{~km}$ for DFSM, MSSG and NICAM and $20 \mathrm{~km}$ for GSM. A TC centre is defined as a minimum SLP point from the predicted mean SLP field smoothed 100 times by a 1-2-1 filter for each longitude and latitude. The initial TC centre is defined within a radius of $1^{\circ}$ from a centre position based on the RSMC Tokyo best-track data. The next centre position is defined as the minimum SLP point from the smoothed SLP field within a radius of $1^{\circ}$ from the previous centre position. The tracking terminates when the minimum SLP points reach a proximity of $1^{\circ}$ from the lateral boundary in the domain of the output data or the difference between the minimum SLP and an ambient SLP defined as an areal average within $500 \mathrm{~km}$ of the minimum SLP point is less than $1 \mathrm{hPa}$. The tracking algorithm works well for nearly all cases; however, misdetection occurred for some very weak TCs. These cases were excluded from the validation.

\subsection{AR50 and AR30}

The RSMC Tokyo best-track data contain longest and shortest radii of 50-knot and 30-knot wind speeds and their direction. AR50 and AR30 are defined as the average of the longest and shortest radii of the 50-knot and 30-knot wind speeds, respectively. The directions of the longest and shortest radii are defined by eight directions (N, NE, E, SE, S, SW, $\mathrm{W}$ and $\mathrm{NW}$ ) in the best-track data. Therefore, we calculated the radii of the 50-knot and 30-knot wind in the model in each of the eight directions first and then determined the direction of the longest and shortest radii. Then, the radii in those two directions were averaged to obtain AR50 and AR30.

\subsection{Multi-model ensemble mean}

The multi-model ensemble mean (MME) is applied to the three $7 \mathrm{~km}$ mesh models (DFSM, MSSG and NICAM). 


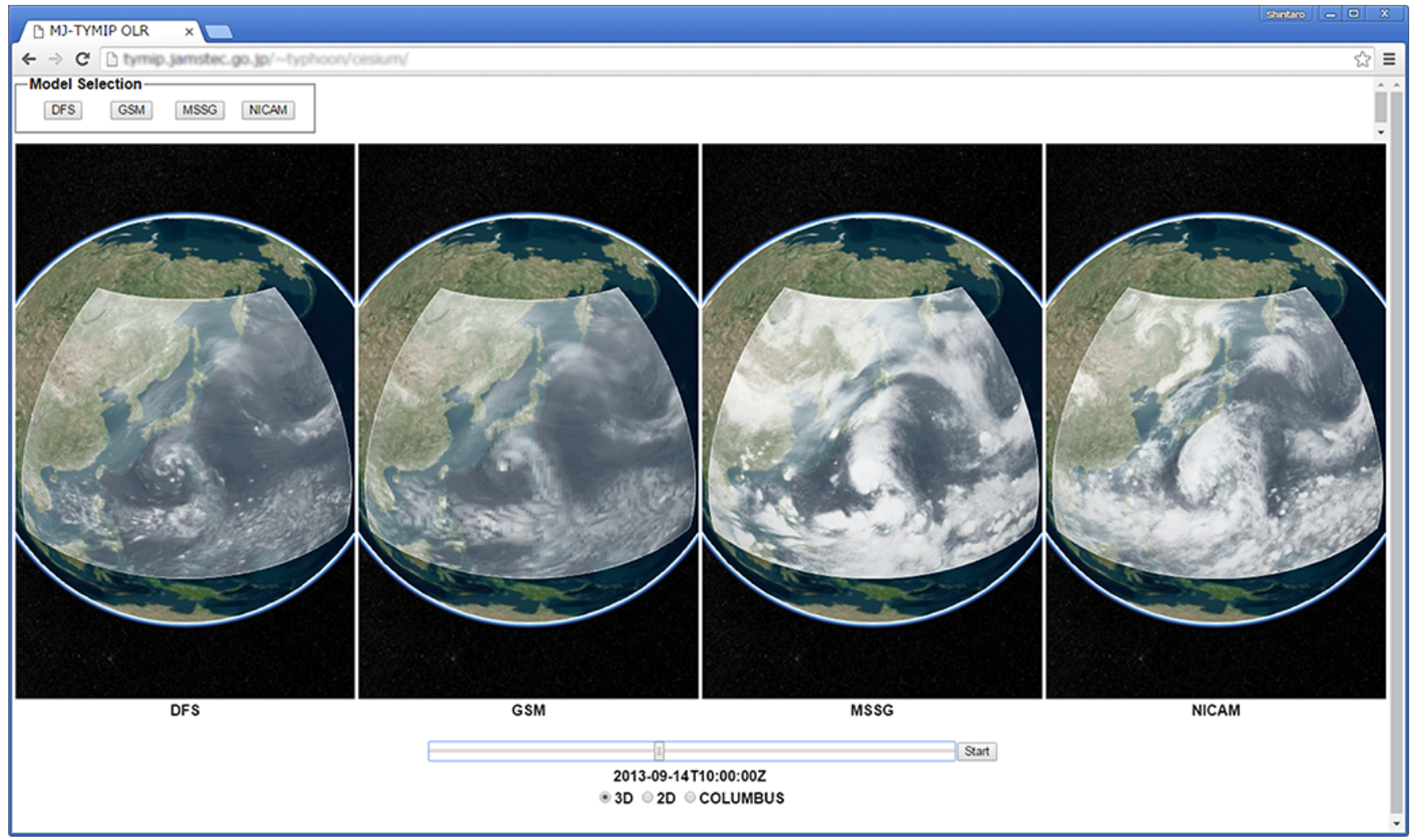

Figure 2. Screen capture of the web application: outgoing longwave radiation at 14 September 2013, 10:00:00 UTC, simulated in experiments initialized at 12 September 2013, 06:00:00 UTC.

MME is a simple ensemble average derived from a combination of individual models, which reduces the average forecast error relative to the best individual predictions by the individual models. MME also provides additional information about the forecast uncertainty, enhancing forecast confidence (Goerss, 2000; Yamaguchi et al., 2012).

\subsection{Visualization}

We developed a web application that allows the simultaneous visualization of multi-model results. Figure 2 shows a screen capture of this application, which portrays digital globes using Cesium.js (Analytical Graphics, Inc., http: //cesiumjs.org), a WebGL-based virtual globe and map engine. Visualization results of each model are overlaid on them. We used the Volume Data Visualizer for Google Earth (VDVGE; Kawahara, 2012; Kawahara et al., 2015) to depict visualization results for the overlay. VDVGE is originally a visualization software that exports visualization results in the KML format, a data format suitable for Google Earth. An option to export in the CZML format, suitable for Cesium.js, has recently been implemented in VDVGE. The present web application enables us to view the animation display for time-series visualization results of each model while synchronously changing the three-dimensional viewpoint. An option to display each model result selectively is also available. This application enables the four models to be easily compared.

\section{Results}

\subsection{Computational resources}

Computational performance is an important metric for an operational numerical weather forecast model. DFSM, MSSG and NICAM models consumed computational resources equivalent to 682,2330 and 1155 node hours, respectively, for a case on 12 September 2013, 00:00:00 UTC. These quantities did not vary greatly between cases because the computational nodes were occupied in each calculation and the disk I/O was executed from/to the work disk mounted on each computational node. Note that the computational resources required for each model are highly dependent on the model specifications (e.g. the physics scheme, advection scheme, number of vertical layers, vertical resolution and time step) and the degree of optimization for the Earth Simulator. 


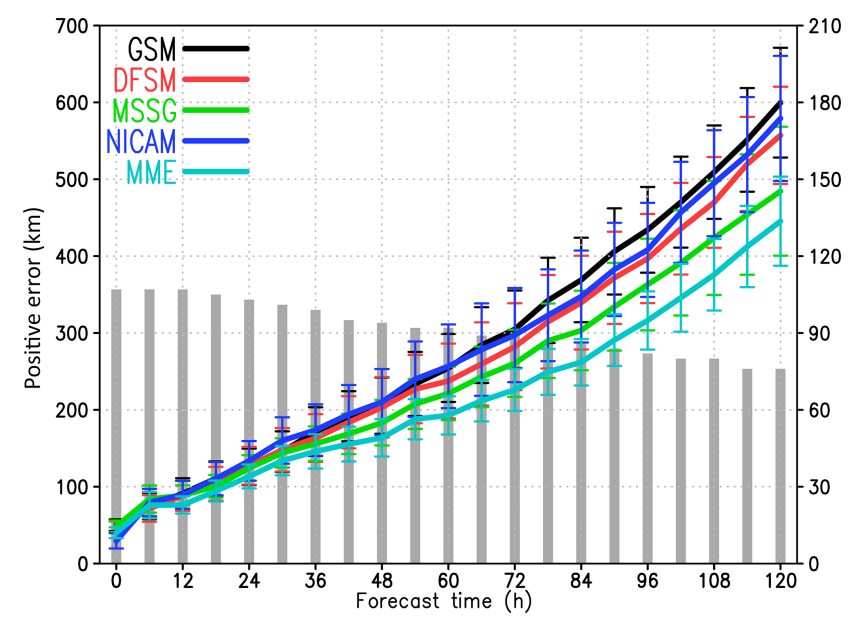

Figure 3. Errors in the track prediction for GSM, DFSM, MSSG, NICAM and MME (in the second stage). Each grey bar indicates the number of samples at each forecast time (right-vertical axis). Error bars indicate $95 \%$ confidence levels of the central pressure difference between the prediction and the RSMC Tokyo best-track data.

\subsection{Track predictions}

To quantify the advantage of using finer resolutions for TC track prediction, we examined the time series of TC track prediction errors with reference to the RSMC Tokyo best track for the second stage (Fig. 3). TC track predictions by DFSM, MSSG and NICAM performed better than GSM. However, the reduction in the track errors depended on the TC case. That is, the use of finer resolution alone does not always improve TC track prediction. This suggests that improvements in the initial conditions and those of the physical processes in each model are also required to improve track prediction.

We also validated MME using track predictions of the three models with reference to the RSMC Tokyo best-track data. MME track prediction gave the smallest track errors for forecast time (FT) of $24-120 \mathrm{~h}$. The reduction rate of the MME position error from that of GSM was $\sim 26 \%$ at $\mathrm{FT}=120 \mathrm{~h}$ relative to that of GSM. The position error of MME at that FT corresponds to that of GSM at FT $=96 \mathrm{~h}$. Even though MME had promising results with regard to improving TC track prediction, future work is required to achieve more robust results and to answer scientific and practical questions, such as in which cases MME is effective and why.

\subsection{Intensity predictions}

Figure 4 shows time series of the average central pressure and the standard deviation in each model relative to the RSMC Tokyo best-track data for the second stage. Because the global objective analysis data, which were used as initial conditions of the numerical experiments, tend to reproduce TC

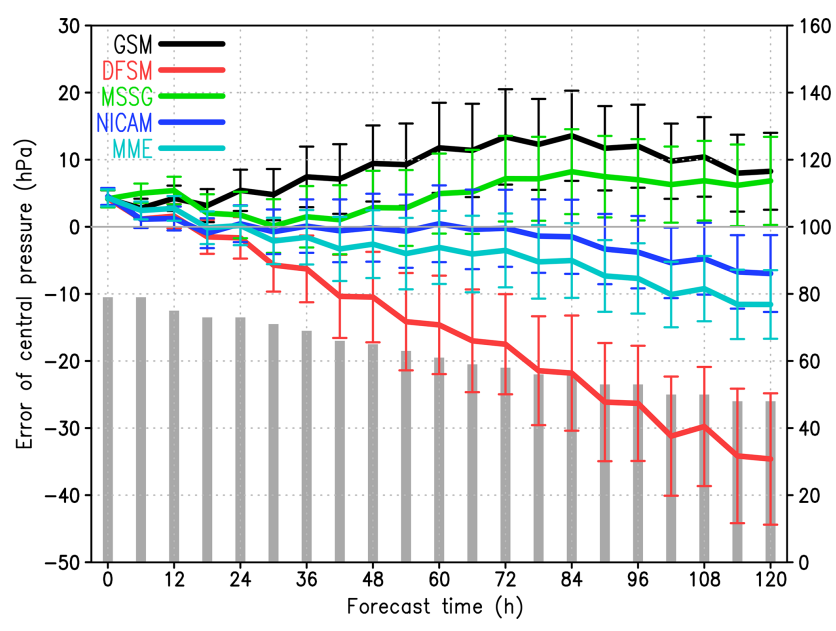

Figure 4. Errors in the predictions of the central pressure for GSM, DFSM, MSSG, NICAM and MME (in the second stage). Each grey bar indicates the number of samples at each forecast time (rightvertical axis). Error bars indicate $95 \%$ confidence levels of the central pressure difference between the prediction and the RSMC Tokyo best-track data.

central pressure shallower than those in RSMC Tokyo besttrack data, cases with an initial bias $<20 \mathrm{hPa}$ are validated. The central pressures in MSSG and NICAM showed relatively small biases compared to the error in GSM. These results indicate that these $7 \mathrm{~km}$ mesh models help decrease systematic positive errors for the central pressure. However, the central pressure in DFSM showed over-intensification and the magnitude of the bias after FT $=54 \mathrm{~h}$ became larger than that in GSM. Because both DFSM and GSM had the same specifications except for the horizontal resolution, this result suggests that the improvement of physics schemes suitable for such high-resolution models is needed for accurate forecasts of the central pressure. GSM showed a gradual growth of positive bias in the central pressure until $\mathrm{FT}=84 \mathrm{~h}$, including the initial $24 \mathrm{~h}$, when the $7 \mathrm{~km}$ mesh models showed a continuous reduction in the errors. After this early reduction, the errors of the $7 \mathrm{~km}$ mesh models began to grow in model-specific ways. MSSG showed a gradual growth of positive bias in the central pressure until $\mathrm{FT}=84 \mathrm{~h}$ and then the errors become saturated. NICAM retained nearly no bias for the central pressure until FT $=84 \mathrm{~h}$ and then showed a slight growth in the negative bias for the central pressure until $\mathrm{FT}=120 \mathrm{~h}$. DFSM had a gradual growth of negative bias for the central pressure until FT $=120 \mathrm{~h}$. MME showed a negative bias for the central pressure after FT $=24 \mathrm{~h}$.

\subsection{Predictions of the TC wind structure}

Accurate predictions of AR50 and AR30 lead to accurate estimations of the area affected by TCs. Figure 5 shows the validation result of AR50 based on the RSMC Tokyo besttrack data. All models had negative bias of $80-90 \mathrm{~km}$ even 


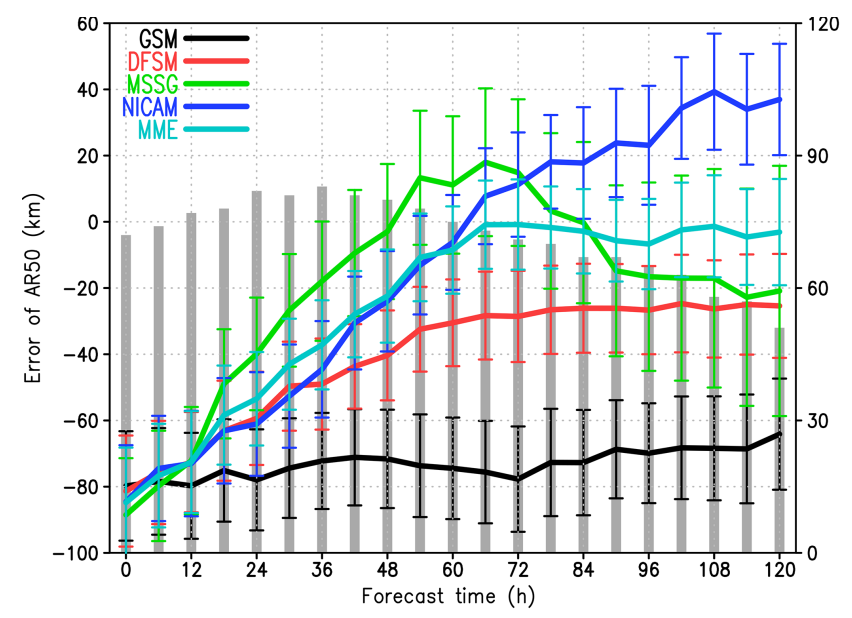

Figure 5. Errors in the averaged radius of the 50-knot wind (AR50) for GSM, DFSM, MSSG, NICAM and MME (in the second stage). Each grey bar indicates the number of samples at each forecast time (right-vertical axis). Error bars indicate $95 \%$ confidence levels of the AR50 difference between the prediction and the RSMC Tokyo best-track data.

at the initial time. This negative bias is partially attributed to the shallower estimation of the central pressure by $\sim 5 \mathrm{hPa}$ (Fig. 4) associated with the biases in the global objective analysis data, which were used as initial conditions of the numerical experiments. The difference in the interpolation methods to prepare the initial data for each model might also affect the bias. The negative biases of all $7 \mathrm{~km}$ models decrease in the early stage. The negative bias of DFSM monotonically decreases until FT $=78 \mathrm{~h}$ and then saturates at $\sim 25 \mathrm{~km}$ at $\mathrm{FT}=78-120 \mathrm{~h}$. The bias of MSSG decreases more rapidly until $\mathrm{FT}=48 \mathrm{~h}$ and becomes positive until $\mathrm{FT}=84 \mathrm{~h}$ and then returns to a negative bias of $\sim 20 \mathrm{~km}$. The bias of NICAM continuously decreases until FT $=66 \mathrm{~h}$ and then becomes positive. At FT $=120 \mathrm{~h}$, NICAM shows a positive bias of $40 \mathrm{~km}$, which was a smaller magnitude than that of the initial bias. Conversely, GSM shows little improvement in the negative bias so that its negative bias remains at $\sim 60 \mathrm{~km}$ at $\mathrm{FT}=120 \mathrm{~h}$. These results show that high-resolution models can significantly reduce the error of AR50. In addition, MME has a promising result in improving the AR50 prediction: MME showed a bias of nearly zero for $\mathrm{FT}=60-120 \mathrm{~h}$.

Figure 6 shows the validation results of AR30. All models show a negative bias of more than $200 \mathrm{~km}$ at FT $=0 \mathrm{~h}$. The negative biases of all $7 \mathrm{~km}$ models tended to decrease in the early stage as FT proceeded. The negative bias of DFSM decreases to $180 \mathrm{~km}$ by FT $=36 \mathrm{~h}$ and then relatively slowly decreases to $150 \mathrm{~km}$ by FT $=120 \mathrm{~h}$. The negative bias of MSSG temporarily increases in the first $6 \mathrm{~h}$, and then decreases. The bias of NICAM continuously decreases up to FT $=120 \mathrm{~h}$, resulting in a negative bias as small as $35 \mathrm{~km}$ at FT $=120 \mathrm{~h}$. GSM had little improvement in AR30 up to FT $=96 \mathrm{~h}$ and

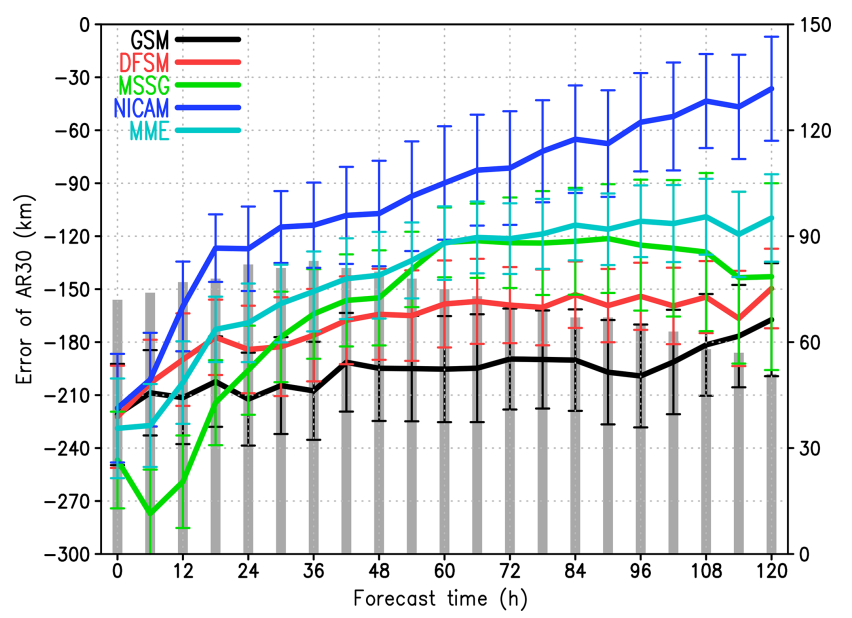

Figure 6. Errors in the averaged radius of the 30-knot wind (AR30) for GSM, DFSM, MSSG, NICAM and MME (in the second stage). Each grey bar indicates the number of samples at each forecast time (right-vertical axis). Error bars indicate $95 \%$ confidence levels of the AR30 difference between the prediction and the RSMC Tokyo best-track data.

shows a negative bias of $\sim 170 \mathrm{~km}$ at FT $=120 \mathrm{~h}$. These results show that high-resolution models can also reduce the error in AR30. However, all the models still had relatively large negative biases compared to the error in AR50. Towards a better prediction of TC wind structure, further improvements in the quality of the objective analysis and the models themselves are needed. The bias of MME also decreases up to $\mathrm{FT}=120 \mathrm{~h}$; however, its magnitude is larger than that of NICAM. Interestingly, DFSM tended to simulate the small wind radii (AR50 and AR30) despite the largest negative bias for central pressure. NICAM and MSSG, which had smaller biases for central pressure, tended to simulate larger wind radii than DFSM. Therefore, it is expected that simulated TCs in NICAM and MSSG have horizontally broader structure than that in DFSM. These results imply that internal dynamics of modelled TC are significantly different among those models. Further studies are needed to understand the differences in internal dynamics of modelled TC by changing physics parameterization and dynamical core.

An accurate prediction of the three-dimensional TC structure can lead to accurate predictions of the intensity, AR30 and AR50. Because there is no high-resolution TC observation that is suitable for the validation of the simulated TC structure, here we made an intercomparison of the TC wind structures simulated by the $7 \mathrm{~km}$ models and $20 \mathrm{~km}$ mesh GSM. Figure 7 shows a composite of the radius-height section of the azimuthal mean radial and tangential wind speeds for TCs at the time of the RSMC Tokyo best-track central pressure between 920 and $940 \mathrm{hPa}$, corresponding, in the life cycle, to the mature stage of a TC. A total of 347 snapshots were used for the composite analysis. If the models can simulate the TC structure perfectly, the result should be the same 


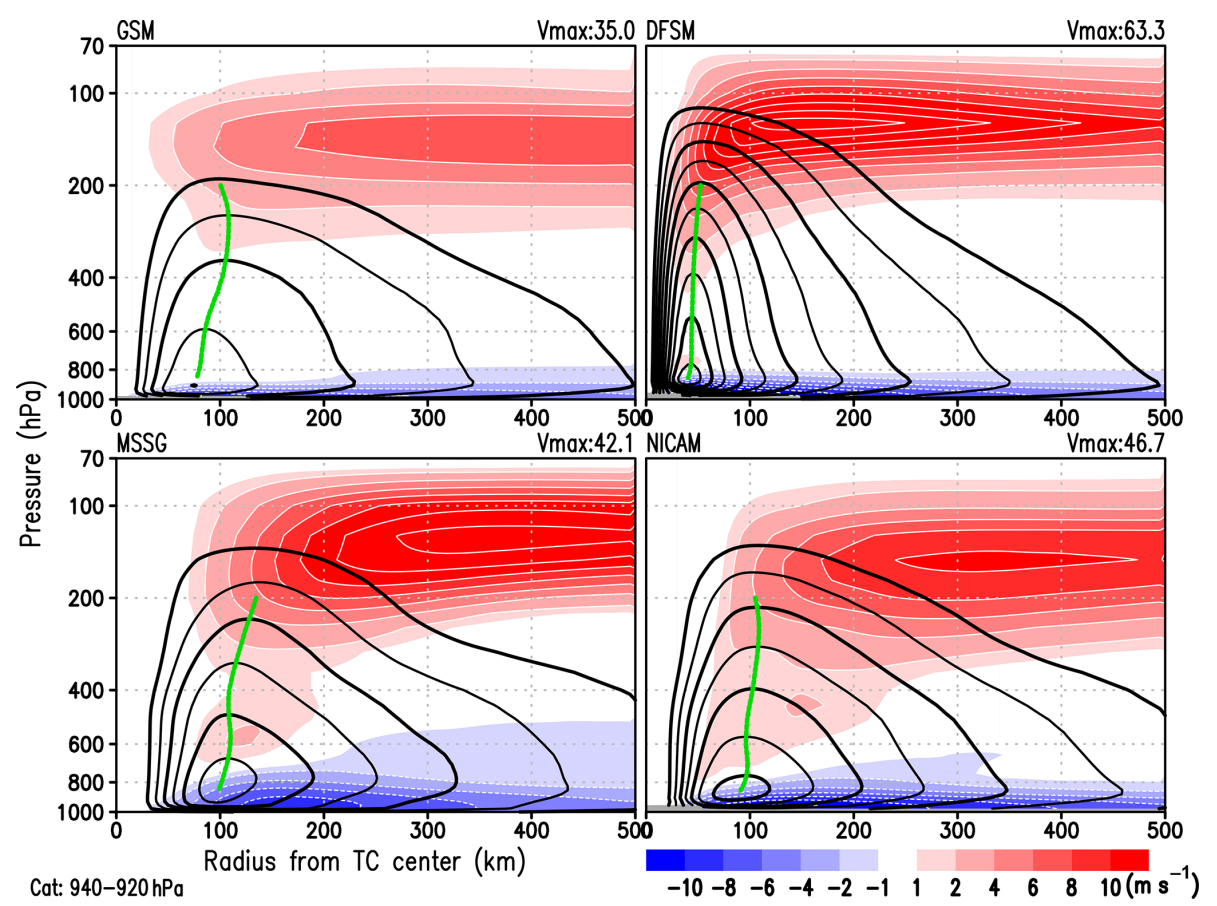

Figure 7. Composite analysis of the radius-height cross section of the axisymmetric mean radial (shaded) and tangential (contour) wind speed for TCs at the time of the analysed central pressure between 920 and $940 \mathrm{hPa}$ in the RSMC Tokyo best-track data. Contour intervals are $5 \mathrm{~m} \mathrm{~s}^{-1}$ (values greater than $15 \mathrm{~m} \mathrm{~s}^{-1}$ are plotted). The green line depicts the RMW between 850 and $200 \mathrm{hPa}$. The grey shading at the bottom of each panel is below the surface.

for all models. While all $7 \mathrm{~km}$ mesh models reproduced typical axisymmetric mean inner-core structures, such as primary and secondary circulations, the simulated TC structures differed significantly between the $7 \mathrm{~km}$ models as expected above. The TCs calculated by DFSM had the highest maximum tangential wind speed and the smallest radius of maximum wind (RMW) of the models. In addition, its primary circulation was the deepest, reaching up to $100 \mathrm{hPa}$ in the vertical direction and the narrowest in the horizontal direction. The depth of the inflow and outflow layers in DFSM was relatively thin and had the strongest radial velocity. The TCs in NICAM and MSSG showed relatively similar structures to each other; however, MSSG had thicker inflow and outflow layers. Differences in the heating and inertial stability in the inner core led to differences in the primary and secondary circulation (Shapiro and Willoughby 1982). Understanding the cause of the differences in the simulated structures in the models will lead to improvements in all the models.

\section{Conclusions and future work}

TYMIP-G7 was implemented in two stages from June 2015 through March 2016. The aim of the project was to statistically quantify and understand the advantages of highresolution global atmospheric models to improve 5-day TC track, intensity and wind radii forecasts. We performed nu- merical experiments for multiple TC cases in 137 runs using three $7 \mathrm{~km}$ mesh global nonhydrostatic atmospheric models: DFSM, MSSG and NICAM. We also included a $20 \mathrm{~km}$ mesh global hydrostatic atmospheric model, GSM, on the Earth Simulator of JAMSTEC. We statistically evaluated errors in the TC track, intensity and wind radii predictions with the following primary results.

(C1) The $7 \mathrm{~km}$ models statistically improve both the TC intensity and track predictions, whereas the improvement in the individual TC tracks depends on the case.

(C2) The MME is a promising approach to further enhance the TC track and AR50 predictions.

(C3) The predicted TC structure differs greatly between the three models even though they have the same horizontal resolution.

To follow up the above results to further improve TC prediction, we must answer the following questions.

(Q1) Why are the TC predictions improved by highresolution models?

(Q2) What are the factors that cause the differences in the simulated TC structure (such as the radius of the maximum winds, the eyewall slope, the inflow and outflow layers and the rainbands) in the three $7 \mathrm{~km}$ mesh atmospheric global models? 
To answer (Q1), an intercomparison of forecasts by the $20 \mathrm{~km}$ mesh GSM and the $7 \mathrm{~km}$ mesh models (DFSM, MSSG and NICAM) is the first step. Concerning (Q2), the predicted TC structure depends on the physics schemes, such as cloud microphysics, planetary boundary layer and surface flux, as well as the dynamical core of the model. To understand the impacts of the model physics schemes, sensitivity experiments altering the schemes and/or tuning parameters will be required.

In addition, the following topics are suggested for future work:

(F1) extended-range forecasts, contributing to TC genesis and MJO/BSISO forecasts;

(F2) atmosphere-ocean coupled experiments to examine impacts on TC intensity and track and MJO/BSISO;

(F3) further high-resolution experiments to study impacts of better inner-core representation on TC intensities and tracks; and

(F4) data assimilation to contribute for validating the models and understanding the TC processes and model initializations.

These topics are addressed below.

An advantage of global models for TC prediction over limited-area models is the coverage of multi-scale atmospheric phenomena from a mesoscale vortex to synoptic environments. Because TC genesis strongly depends on synoptic environments modulated by the MJO/BSISO, global models should be used for its forecasting. Indeed, Nakano et al. (2015) and Xiang et al. (2015) showed that TC genesis is predictable up to 2 weeks in advance; this great skill in TC genesis forecasting was attributed to its strong ability to forecast $\mathrm{BSISO} / \mathrm{MJO}$. We are conducting extended-range (longer than 2 weeks) forecast experiments using the four models in several cases and will investigate the advantage of high-resolution modes.

In the present project, atmosphere-only models were used, except for NICAM, which is coupled with a simple slab ocean model. However, studies have shown that fully coupled atmosphere-ocean processes are essential for especially slow-moving, intense TCs (e.g. Yablonsky and Ginis, 2009). Recently, Zarzycki (2016) reproduced sea surface cooling caused by TCs realistically using a global atmospheric model coupled with a slab ocean model with a simple parameterization of ocean turbulent mixing, which is not considered in NICAM, and demonstrated that the cooling led to significant reduction in TC intensity. These processes affect the TC structure and therefore the track and intensity. In addition, a fully coupled atmosphere-ocean model is better for MJO/BSISO forecasts. MSSG is already capable of coupling MSSG-A with MSSG-O (Sasaki et al., 2016; Takahashi et al., 2013). In addition, NICAM has been coupled with the Center for Climate System Research Ocean COmponent Model (COCO; Hasumi, 2006). Therefore, we will use these coupled global models to examine the impacts of global atmosphere-ocean processes on TC forecasts.

To improve the high-resolution models, the validation of simulated phenomena using observations is essential. An understanding of the essential processes and the modelling therefore requires high-resolution spatiotemporal observations. Recent advances in satellite observations furnish quantitatively and qualitatively rich observational data. However, the spatiotemporal resolution is still insufficient for the validation of TC structures simulated by high-resolution models. Aggressively developing data assimilation techniques using satellite observations (e.g. Zhang et al., 2016; Okamoto et al., 2016) is a promising means of obtaining high-resolution, spatiotemporal, three-dimensional TC structures, including those at the cloud convection scale $(\sim \mathrm{O}(1 \mathrm{~km}))$. In addition, applying such cloud-resolving analyses to deriving the initial conditions of high-resolution models may improve TC prediction.

\section{Data availability}

Access to the initial and boundary data for the models and model outputs can be granted upon request, under a collaborative framework between MRI, JAMSTEC and related institutes or universities.

Competing interests. The authors declare that they have no conflict of interest.

Acknowledgements. This project was conducted as "The Earth Simulator Strategic Project with Special Support" of JAMSTEC. All numerical experiments were run on the Earth Simulator (NEC SX-ACE). This study was partly supported by HPCI Strategic Programs for Innovative Research (SPIRE) Field 3, the FLAGSHIP 2020 project of the Ministry of Education, Culture, Sports, Science and Technology (MEXT) and KAKENHI 26282111, 26400475 and 15K05292 of the Japan Society for the Promotion of Science (JSPS). The authors thank Mikiko Ikeda, Yuichi Saitoh and Hiromitsu Fuchigami for supporting the experiments on the Earth Simulator. The authors also acknowledge Hideaki Kawai and Eiki Shindo for the fruitful discussions. The schematic diagram of the NICAM grid was provided by Masaki Satoh.

Edited by: P. Ullrich

Reviewed by: two anonymous referees 


\section{References}

Baba, Y., Takahashi, K., Sugimura, T., and Goto, K.: Dynamical core of an atmospheric general circulation model on a yin-yang grid, Mon. Weather Rev., 138, 3988-4005, doi:10.1175/2010MWR3375.1, 2010.

Bénard, P., Vivoda, J., Mašek, J., Smolíková, P., Yessad, K., Smith, Ch., Brožková, R., and Geleyn, J.-F.: Dynamical kernel of the Aladin-NH spectral limited-area model: Revised formulation and sensitivity experiments, Q. J. Roy. Meteor. Soc., 136, 155-169, doi:10.1002/qj.522, 2010.

Bernardet, L., Tallapragada, V., Bao, S., Trahan, S., Kwon, Y., Liu, Q., Tong, M., Biswas, M., Brown, T., Stark, D., Carson, L., Yablonsky, R., Uhlhorn, E., Gopalakrishnan, S., Zhang, X., Marchok, T., Kuo, B., and Gall, R.: Community support and transition of research to operations for the hurricane weather research and Forecasting model, B. Am. Meteorol. Soc., 96, 953-960, doi:10.1175/BAMS-D-13-00093.1, 2015.

Braun, S. A. and Tao, W.-K.: Sensitivity of high-resolution simulations of Hurricane Bob (1991) to planetary boundary layer parameterizations, Mon. Weather Rev., 128, 3941-3961, 2000.

Bubnová, R., Hello, G., Bénard, P., and Geleyn, J.-F.: Integration of the fully elastic equations cast in the hydrostatic pressure terrainfollowing coordinate in the framework of the ARPEGE/Aladin NWP system, Mon. Weather Rev., 123, 515-535, 1995.

Carr III, L. E. and Elsberry, R. L.: Dynamical tropical cyclone track forecast errors, Part I: Tropical region error sources, Weather Forecast., 15, 641-661, doi:10.1175/15200434(2000)015<0641:DTCTFE>2.0.CO;2, 2000.

Cheong, H.-B.: Application of double Fourier series to the shallowwater equations on a sphere, J. Comput. Phys., 165, 261-287, 2000.

Choi, Y., Kida, S., and Takahashi, K.: The impact of oceanic circulation and phase transfer on the dispersion of radionuclides released from the Fukushima Dai-ichi Nuclear Power Plant, Biogeosciences, 10, 4911-4925, doi:10.5194/bg-10-4911-2013, 2013.

Fairall, C. W., Bradley, E. F., Rogers, D. P., Edson, J. B., and Young, G. S.: Bulk parameterization of air-sea fluxes for Tropical OceanGlobal Atmosphere Coupled-Ocean Atmosphere Response Experiment, J. Geophys. Res., 101, 747-764, 1996.

Fairall, C. W., Bradley, E. F., Hare, J. E., Grachev, A. A., and Edson, J. B.: Bulk parameterization of air-sea fluxes: updates and verification for the COARE algorithm, J. Climate, 16, 571-591, 2003.

Fierro, A. O., Rogers, R. F., Marks, F. D., and Nolan, D. S.: The impact of horizontal grid spacing on the microphysical and kinematic structures of strong tropical cyclones simulated with the WRF-ARW model, Mon. Weather Rev., 137, 3717-3743, doi:10.1175/2009MWR2946.1, 2009.

Fudeyasu, H., Wang, Y., Satoh, M., Nasuno, T., Miura, H., and Yanase, W.: Global cloud-system-resolving model NICAM successfully simulated the lifecycles of two real tropical cyclones, Geophys. Res. Lett., 35, L22808, doi:10.1029/2008GL036003, 2008.

Fudeyasu, H., Wang, Y., Satoh, M., Nasuno, T., Miura, H., and Yanase, W.: Multiscale interactions in the life cycle of a tropical cyclone simulated in a global cloud-system-resolving model, Part I: Large-scale and storm-scale evolutions, Mon. Weather Rev., 138, 4285-4304, doi:10.1175/2010MWR3474.1, 2010a.
Fudeyasu, H., Wang, Y., Satoh, M., Nasuno, T., Miura, H., and Yanase, W.: Multiscale interactions in the life cycle of a tropical cyclone simulated in a global cloud-system-resolving model, Part II: System-scale and mesoscale processes, Mon. Weather Rev., 138, 4305-4327, doi:10.1175/2010MWR3475.1, 2010 b.

Gentry, M. S. and Lackmann, G. M.: Sensitivity of simulated tropical cyclone structure and intensity to horizontal resolution, Mon. Weather Rev., 138, 688-704, doi:10.1175/2009MWR2976.1, 2010.

Goerss, J. S.: Tropical cyclone track forecasts using an ensemble of dynamical models, Mon. Weather Rev., 128, 1187-1193, doi:10.1175/1520-0493(2000)128<1187:TCTFUA>2.0.CO;2, 2000.

Gravel, S. and Staniforth, A.: A mass-conserving semi-Lagraingian scheme for the shallow-water equations, Mon. Weather Rev., 122, 243-248, 1994.

Hasumi, H.: CCSR Ocean Component model (COCO) version 4.0. CCSR Rep 25, The University of Tokyo, Chiba, Japan, 2006.

Hortal, M.: The development and testing of a new two-timelevel semi-Lagrangian scheme (SETTLS) in the ECMWF forecast model, Q. J. Roy. Meteor. Soc., 128, 1671-1687, doi:10.1002/qj.200212858314, 2002.

Ito, K., Kuroda, T., Saito, K., and Wada, A.: Forecasting a large number of tropical cyclone intensities around Japan using a highresolution atmosphere-ocean coupled model, Weather Forecast., 30, 793-808, doi:10.1175/WAF-D-14-00034.1, 2015.

Japan Meteorological Agency (JMA): Outline of the operational numerical weather prediction at the Japan Meteorological Agency, Appendix to WMO technical progress report on the global dataprocessing and forecasting system and numerical weather prediction, 188 pp., available at: http://www.jma.go.jp/jma/jma-eng/ jma-center/nwp/outline2013-nwp/index.htm, 2013.

Japan Meteorological Agency: Annual report on the activities of the RSMC Tokyo-typhoon center, $90 \mathrm{pp}$., available at: http://www.jma.go.jp/jma/jma-eng/jma-center/rsmc-hp-pub-eg/ AnnualReport/2014/Text/Text2014.pdf, 2014.

Japan Meteorological Agency: The upgrade history of the global spectral model, available at: http://www.wis-jma.go.jp/ddb/ latest_modelupgrade.txt, 2016.

Joint Typhoon Warning Center: 2008 Annual tropical cyclone report, 116 pp., available at: http://www.usno.navy.mil/NOOC/ nmfc-ph/RSS/jtwc/atcr/2008atcr.pdf, 2008.

Kageyama, A. and Sato, T.: The Yin-Yang grid: An overset grid in spherical geometry, Geochem. Geophys. Geosyst., 5, Q09005, doi:10.1029/2004GC000734, 2004.

Kajikawa, Y., Miyamoto, Y., Yoshida, R., Yamaura, T., Yashiro, H., and Tomita, H.: Resolution dependence of deep convections in a global simulation from over 10-kilometer to sub-kilometer grid spacing, Prog. Earth Planet. Sci., 3, 16, doi:10.1186/s40645-0160094-5, 2016.

Kanada, S. and Wada, A.: Numerical study on the extremely rapid intensification of an intense tropical cyclone, Typhoon Ida (1958), J. Atmos. Sci., 72, 4194-4217, doi:10.2151/jmsj.2015037, 2015.

Kawahara, S.: Volume Data Visualizer for Google Earth $^{\text {TM }}$ (VDVGE), http://www.jamstec.go.jp/ceist/aeird/avcrg/vdvge.en. html, (accessed 27 April 2016), 2012. 
Kawahara, S., Onishi, R., Goto, K., and Takahashi, K.: Realistic representation of clouds in Google Earth, Proc. SIGGRAPH Asia 2015 VHPC, doi:10.1145/2818517.2818541, 2015.

Kobayashi, S., Ota, Y., Harada, Y., Ebita, A., Moriya, M., Onoda, H., Onogi, K, Kamahori, H., Kobayashi, C., Endo, H., Miyaoka, K., and Takahashi, K.: The JRA-55 reanalysis: General specifications and basic characteristics, J. Meteor. Soc. Jpn., 93, 5-48, doi:10.2151/jmsj.2015-001, 2015.

Kodama, C., Yamada, Y., Noda, A. T., Kikuchi, K., Kajikawa, Y., Nasuno, T., Tomita, T., Yamaura, T., Takahashi, T. G., Hara, M., Kawatani, Y., Satoh, M., and Sugi, M.: A 20-year climatology of a NICAM AMIP-type simulation, J. Meteor. Soc. Jpn., 93, 393424, doi:10.2151/jmsj.2015-024, 2015.

Kurihara, Y., Sakurai, T., and Kuragano, T.: Global daily sea surface temperature analysis using data from satellite microwave radiometer, satellite infrared radiometer and in-situ observations, Weather Bull., 73, s1-s18, 2006 (in Japanese).

Louis, J. F.: A parametric model of vertical eddy fluxes in the atmosphere, Bound.-Lay. Meteor., 2, 187-202, 1979.

Louis, J. F., Tiedtke, M., and Geleyn, J. F.: A short history of the operational PBL parameterization at ECMWF, Proc. Workshop on Planetary Boundary Layer Parameterization, Reading, UK, ECMWF, 59-79, 1982.

Lu, L.-F., Onishi, R., and Takahashi, K.: The effect of wind on long-term summer water temperature trends in Tokyo Bay, Japan, Ocean Dynam., 65, 919-930, doi:10.1007/s10236-015-0848-4, 2015.

Madden, R. A. and Julian, P. R.: Description of global-scale circulation cells in the tropics with a 40-50 day period, J. Atmos. Sci., 29, 1109-1123, 1972.

Matsueda, M. and Endo, H.: Verification of medium-range MJO forecasts with TIGGE, Geophys. Res. Lett., 38, L11801, doi:10.1029/2011GL047480, 2011.

Mellor, G. L. and Yamada, T.: A hierarchy of turbulence closure models for planetary boundary layers, J. Atmos. Sci., 31, 17911806, 1974.

Mellor, G. L. and Yamada, T.: Development of a turbulence closure model for geophysical fluid problems, Rev. Geophys. Space Phys., 20, 851-875, 1982.

Miller, M. J., Palmer, T. N., and Swinbank, R.: Parameterization and influence of subgridscale orography in general circulation and numerical weather prediction models, Meteor. Atmos. Phys., 40, 84-109, 1989.

Miura, H., Satoh, M., Tomita H., Noda, A. T., Nasuno, T., and Iga, S.: A short-duration global cloud-resolving simulation with a realistic land and sea distribution, Geophys. Res. Lett., 34, L02804, doi:10.1029/2006GL027448, 2007a.

Miura, H., Satoh, M., Nasuno T., Noda, A. T., and Oouchi, K.: A Madden-Julian oscillation event realistically simulated by a global cloud-resolving model, Science, 318, 1763-1765, doi:10.1126/science.1148443, 2007b.

Miyakawa, T., Satoh, M., Miura, H., Tomita, H., Yashiro, H., Noda, A. T., Yamada, Y., Kodama, C., Kimoto, M., and Yoneyama, K.: Madden-Julian oscillation prediction skill of a new-generation global model demonstrated using a supercomputer, Nat. Comm., 5, 3769, doi:10.1038/ncomms4769, 2014.

Miyamoto, K.: Introduction of the reduced Gaussian grid into the operational global NWP model at JMA, CAS/JSC WGNE Re- search Activities in Atmospheric and Ocean Modelling, 36, 6.96.10, 2006.

Miyamoto, Y., Kajikawa, Y., Yoshida, R., Yamaura, T., Yashiro, H., and Tomita, H.: Deep moist atmospheric convection in a subkilometer global simulation, Geophys. Res. Lett., 40, 4922-4926, doi:10.1002/grl.50944, 2013.

Miyamoto, Y., Yoshida, R., Yamaura, T., Yashiro, H., Tomita, H., and Kajikawa, Y.: Does convection vary in different cloud disturbances?, Atmos. Sci. Lett., 16, 305-309, doi:10.1002/as12.558, 2015.

Miyoshi, T., Kondo, K., and Terasaki, K.: Big ensemble data assimilation in numerical weather prediction, Computer, 48, 15-21, doi:10.1109/MC.2015.332, 2015.

Mizuta, R., Oouchi, K., Yoshimura, H., Noda, A., Katayama, K., Yukimoto, S., Hosaka, M., Kusunoki, S., Kawai, H., and Nakagawa, M.: 20-km-mesh global climate simulations using JMAGSM model - mean climate states, J. Meteor. Soc. Jpn., 84, 165185, doi:10.2151/jmsj.84.165, 2006.

Moon, I.-J., Ginis, I., Hara, T., and Thomas, B.: A physics-based parameterization of air-sea momentum flux at high wind speeds and its impact on hurricane intensity predictions, Mon. Weather Rev., 135, 2869-2878, doi:10.1175/MWR3432.1, 2007.

Murakami, H. and Sugi, M.: Effect of model resolution on tropical cyclone climate projections, SOLA, 6, 73-76, doi:10.2151/sola.2010-019, 2010.

Murakami, H., Mizuta, R., and Shindo, E.: Future changes in tropical cyclone activity projected by multi-physics and multiSST ensemble experiments using the 60-km-mesh MRI-AGCM, Clim. Dynam., 39, 2569-2584, doi:10.1007/s00382-011-1223-x, 2012a.

Murakami, H., Wang, Y., Yoshimura, H., Mizuta, R., Sugi, M., Shindo, E., Adachi, Y., Yukimoto, S., Hosaka, M., Kusunoki, S., Ose, T., and Kitoh, A.: Future changes in tropical cyclone activity projected by the new high-resolution MRI-AGCM, J. Climate, 25, 3237-3260, doi:10.1175/JCLI-D-11-00415.1, 2012b.

Nakanishi, M. and Niino, H.: An improved Mellor-Yamada level3 model with condensation physics: Its design and verification, Bound.-Lay. Meteor., 112, 1-31, 2004.

Nakanishi, M. and Niino, H.: Development of an Improved Turbulence Closure Model for the Atmospheric Boundary Layer, J. Meteor. Soc. Jpn., 87, 895-912, doi:10.2151/jmsj.87.895, 2009.

Nakano, M., Nasuno, T., Sawada, M., and Satoh, M.: Intraseasonal variability and tropical cyclogenesis in the western North Pacific simulated by a global nonhydrostatic atmospheric model, Geophys. Res. Lett., 42, 565-571, doi:10.1002/2014GL062479, 2015.

Nasuno, T.: Forecast skill of Madden-Julian oscillation events in a global nonhydrostatic model during the CINDY2011/DYNAMO observation period, SOLA, 9, 69-73, doi:10.2151/sola.2013016, 2013.

Nasuno, T., Yamada, H., Nakano, M., Kubota, H., Sawada, M., and Yoshida, R.: Global cloud-permitting simulations of Typhoon Fengshen (2008), Geosci. Lett., 3, 32, doi:10.1186/s40562-0160064-1, 2016.

Noda, A. T., Oouchi, K., Satoh, M., Tomita, H., Iga, S.I., and Tsushima, Y.: Importance of the subgrid-scale turbulent moist process: Cloud distribution in global cloud-resolving simulations, Atmos Res., 96, 208-217, doi:10.1016/j.atmosres.2009.05.007, 2010. 
Okamoto, K., Aonashi, K., Kubota, T., and Tashima, T.: Experimental assimilation of the GPM-Core DPR reflectivity profiles for Typhoon Halong (2014), Mon. Weather Rev., 144, 2307-2326, doi:10.1175/MWR-D-15-0399.1, 2016.

Onishi, R. and Takahashi, K.: A warm-bin-cold-bulk hybrid cloud microphysical model, J. Atmos. Sci., 69, 1474-1497, doi:10.1175/JAS-D-11-0166.1, 2012.

Onishi, R., Takahashi, K., and Komori, S.: High-resolution simulations for turbulent clouds developing over the ocean, in: Gas Transfer at Water Surfaces, edited by: Komori, S., McGillis, W., and Kurose, R., Kyoto University Press, 6, 582-592, 2011.

Onogi, K., Tsutsui, J., Koide, H., Sakamoto, M., Kobayashi, S., Hatsushika, H., Matsumoto, T., Yamazaki, N., Kamahori, H., Takahashi, K., Kadokura, S., Wada, K., Kato, K., Oyama, R., Ose, T., Mannoji, N., and Taira, R.: The JRA-25 Reanalysis, J. Meteor. Soc. Jpn., 85, 369-432, doi:10.2151/jmsj.85.369, 2007.

Oouchi, K., Noda, A. T., Satoh, M., Miura, H., Tomita, H., Nasuno, T., and Iga, S.: A simulated preconditioning of typhoon genesis controlled by a boreal summer Madden-Julian Oscillation event in a global cloud-resolving mode, SOLA, 5, 65-68, doi:10.2151/sola.2009-017, 2009.

Priestley, A.: A quasi-conservative version of the semi-Lagrangian advection scheme, Mon. Weather Rev., 121, 621-629, 1993.

Randall, D. and Pan, D.-M.: Implementation of the ArakawaSchubert cumulus parameterization with a prognostic closure, The representation of cumulus convection in numerical models, AMS Meteor. Monogr. Series, 46, 137-144, 1993.

Randall, D., Khairoutdinov, M., Arakawa, A., and Grabowski, W.: Breaking the cloud parameterization deadlock, B. Am. Meteorol. Soc., 84, 1547-1564, doi:10.1175/BAMS-84-11-1547, 2003.

Rogers, R. F., Reasor, P., and Lorsolo, S.: Airborne doppler observations of the inner-core structural differences between intensifying and steady-state tropical cyclones, Mon. Weather Rev., 141, 2970-2991, doi:10.1175/MWR-D-12-00357.1, 2013.

Sasaki, W., Onishi, R., Fuchigami, H., Goto, K., Nishikawa, S., Ishikawa, Y., and Takahashi, K.: MJO simulation in a cloudsystem-resolving global ocean-atmosphere coupled model, Geophys. Res. Lett., 43, 9352-9360, doi:10.1002/2016GL070550, 2016.

Satoh, M., Matsuno, T., Tomita, H., Miura, H., Nasuno, T., and Iga, S.: Nonhydrostatic icosahedral atmospheric model (NICAM) for global cloud resolving simulations, J. Comput. Phys., 227, 34863514, doi:10.1016/j.jcp.2007.02.006, 2008.

Satoh, M., Tomita, H., Yashiro, H., Miura, H, Kodama, C., Seiki, T., Noda, A. T., Yamada, Y., Goto, D., Sawada, M., Miyoshi, T., Niwa, Y., Hara, M., Ohno, T., Iga, S., Arakawa, T., Inoue, T., and Kubokawa, H.: The non-hydrostatic icosahedral atmospheric model: description and development, Prog. Earth Planet. Sci., 1, 18, doi:10.1186/s40645-014-0018-1, 2014.

Sekiguchi, M. and Nakajima, T.: A k-distribution-based radiation code and its computational optimization for an atmospheric general circulation model, J. Quant. Spectrosc. Ra., 109, 2779-2793, doi:10.1016/j.jqsrt.2008.07.013, 2008.

Shibata, K., Yoshimura, H., Ohizumi, M., Hosaka, M., and Sugi, M.: A simulation of troposphere, stratosphere and mesosphere with MRI/JMA98 GCM, Pap. Meteor. Geophys., 50, 15-53, 1999.
Shapiro, L. J. and Willoughby, H. E.: The response of balanced hurricanes to local sources of heat and momentum, J. Atmos. Sci., 39, 378-394, 1982.

Smith, R. N. B.: A scheme for predicting layer clouds and their water content in a general circulation model, Q. J. Roy. Meteor. Soc., 116, 435-460, 1990.

Takahashi, K., Peng, X., Ohnishi, R., Sugimura, T., Ohdaira, M., Goto, K., and Fuchigami, H.: Multi-scale weather/climate simulations with Multi-Scale Simulator for the Geoenvironment (MSSG) on the Earth Simulator, Ann. Rep. Earth Simulator Center, April 2006-March 2007, 27-33, ISSN 1348-5822, 2006

Takahashi, K., Onishi, R., Baba, Y., Kida, S., Matsuda, K., Goto, K., and Fuchigami, H.: Challenge toward the prediction of typhoon behaviour and down pour, J. Phys. Conference Series, 454, 012072, 2013.

Takata, K., Emori, S., and Watanabe, T.: Development of the minimal advanced treatments of surface interaction and runoff, Global Planet. Change, 38, 209-222, 2003.

Taniguchi, H., Yanase, W., and Satoh, M.: Ensemble simulation of cyclone Nargis by a global cloud-system-resolving model-modulation of cyclogenesis by the Madden-Julian oscillation, J. Meteor. Soc. Jpn., 88, 571-591, doi:10.2151/jmsj.2010317, 2010.

Tomita, H.: New microphysical schemes with five and six categories by diagnostic generation of cloud ice, J. Meteorol. Soc. Jpn., 86 , 121-142, doi:10.2151/jmsj.86A.121, 2008.

Tomita, H., Tsugawa, M., Satoh, M., and Goto, K.: Shallow water model on a modified icosahedral geodesic grid by using spring dynamics, J. Comp. Phys., 174, 579-613, doi:10.1006/jcph.2001.6897, 2001.

Toro, E. F.: A weighted average flux method for hyperbolic conservation laws, P. R. Soc. London, 423, 401-418, 1989.

Wang, B. and Rui, H.: Synoptic climatology of transient tropical intraseasonal convection anomalies: 1975-1985, Meteorol. Atmos. Phys., 44, 43-61, 1990.

Wang, B. and Xie, X.: A model for the boreal summer intraseasonal oscillation, J. Atmos. Sci., 54, 72-86, 1997.

Wang, H. and Wang, Y.: A numerical study of typhoon Megi (2010): Part I: Rapid intensification, Mon. Weather Rev., 142, 29-48, doi:10.1175/MWR-D-13-00070.1, 2014.

Wedi, N. P. and Smolarkiewicz, P. K.: A framework for testing global non-hydrostatic models, Q. J. Roy. Meteor. Soc., 135, 469-484, doi:10.1002/qj.377, 2009.

Wicker, L. J. and Skamarock, W. C.: Time-split-ting methods for elastic models using forward time schemes, Mon. Weather Rev., 130, 2088-2097, 2002.

Xiang, B., Lin, S.-J., Zhao, M., Zhang, S., Vecchi, G., Li, T., Jiang, X., Harris, L., and Chen, J.-H.: Beyond weather timescale prediction for hurricane Sandy and super typhoon Haiyan in a global climate model, Mon. Weather Rev., 143, 524-535, doi:10.1175/MWR-D-14-00227.1, 2015.

Yablonsky, R. M. and Ginis, I.: Limitation of onedimensional ocean models for coupled hurricane-ocean model forecasts, Mon. Weather Rev., 137, 4410-4419, doi:10.1175/2009MWR2863.1, 2009.

Yabu, S.: Development of longwave radiation scheme with consideration of scattering by clouds in JMA global model, CAS/JSC WGNE Research Activities in Atmospheric and Oceanic Modelling, 43, 4.07-4.08, 2013. 
Yamada, H., Nasuno, T., Yanase, W., and Satoh, M.: Role of the vertical structure of a simulated tropical cyclone in its motion: A case study of Typhoon Fengshen (2008), SOLA, 12, 203-208, doi:10.2151/sola.2016-041, 2016.

Yamaguchi, M., Iriguchi, T., Nakazawa, T., and Wu, C.-C.: An observing system experiment for Typhoon Conson (2004) using a singular vector method and DOTSTAR data, Mon. Weather Rev., 137, 2801-2816, 2009.

Yamaguchi, M., Nakazawa, T., and Hoshino, S.: On the relative benefits of a multi-centre grand ensemble for tropical cyclone track prediction in the western North Pacific, Q. J. Roy. Meteor. Soc., 138, 2019-2029, doi:10.1002/qj.1937, 2012.

Yamaguchi, M., Vitart, F., Lang, S. T. K., Magnusson, L., Elsberry, R. L., Elliott, G., Kyouda, M., and Nakazawa, T.: Global distribution on the skill of tropical cyclone activity forecasts from shortto medium-range time scales, Weather Forecast., 30, 1695-1709, doi:10.1175/WAF-D-14-00136.1, 2015.

Yanase, W., Taniguchi, H., and Satoh, M.: The genesis of tropical cyclone Nargis (2008): Environmental modulation and numerical predictability, J. Meteor. Soc. Jpn., 88, 497-519, doi:10.2151/jmsj.2010-314, 2010.

Yoshimura, H.: Development of a nonhydrostatic global spectral atmospheric model using double Fourier series, CAS/JSC WGNE Research Activities in Atmospheric and Ocean Modeling, 42, 3.05-3.06, 2012.
Yoshimura, H. and Matsumura, T.: A Semi-Lagrangian scheme conservative in the vertical direction, CAS/JSC WGNE Research Activities in Atmospheric and Ocean Modeling, 33, 3.19-3.20, 2003.

Yoshimura, H. and Matsumura, T.: A two-time-level verticallyconservative semi-Lagrangian semi-implicit double Fourier series AGCM, CAS/JSC WGNE Research Activities in Atmospheric and Ocean Modeling, 35, 3.25-3.26, 2005.

Yukimoto, S. and Coauthors: Meteorological Research InstituteEarth System Model Version 1 (MRI-ESM1) - Model Description, Technical Reports of the Meteorological Research Institute, No. 64, 2011.

Zarzycki, C. M.: Tropical cyclone intensity errors associated with lack of two-way ocean coupling in high-resolution global simulations, J. Climate, 29, 8589-8610, doi:10.1175/JCLI-D-160273.1, 2016.

Zhang, D. and Anthes, R. A.: A high-resolution model of the planetary boundary layer-sensitivity tests and comparisons with SESAME-79 Data, J. Appl. Meteor., 21, 1594-1609, 1982.

Zhang, F., Minamide, M., and Clothiaux, E. E.: Potential impacts of assimilating all-sky infrared satellite radiances from GOES-R on convection-permitting analysis and prediction of tropical cyclones, Geophys. Res. Lett., 43, 2954-2963, doi:10.1002/2016GL068468, 2016. 